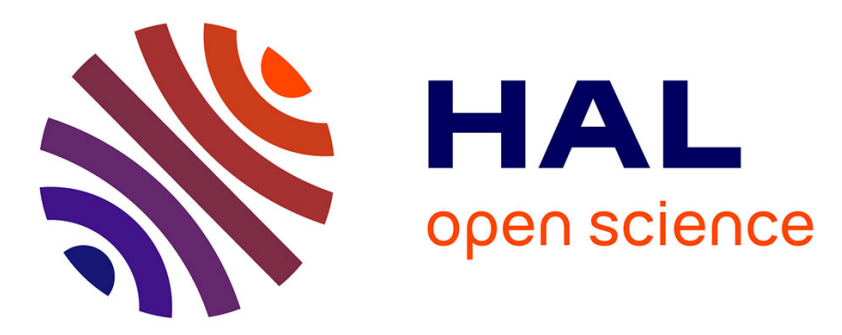

\title{
Can transparency of information reduce embezzlement? Experimental Evidence from Tanzania
}

Salvatore Di Falco, Brice Magdalou, David Masclet, Marie Claire Villeval, Marc Willinger

\section{To cite this version:}

Salvatore Di Falco, Brice Magdalou, David Masclet, Marie Claire Villeval, Marc Willinger. Can transparency of information reduce embezzlement? Experimental Evidence from Tanzania. 2016. halshs-01315697

\author{
HAL Id: halshs-01315697 \\ https://shs.hal.science/halshs-01315697 \\ Preprint submitted on 13 May 2016
}

HAL is a multi-disciplinary open access archive for the deposit and dissemination of scientific research documents, whether they are published or not. The documents may come from teaching and research institutions in France or abroad, or from public or private research centers.
L'archive ouverte pluridisciplinaire HAL, est destinée au dépôt et à la diffusion de documents scientifiques de niveau recherche, publiés ou non, émanant des établissements d'enseignement et de recherche français ou étrangers, des laboratoires publics ou privés. 
UMR 5824

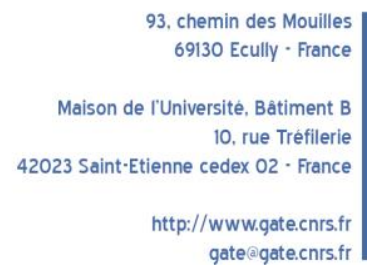

WP 1618 - May 2016

Can transparency of information reduce embezzlement?

Experimental Evidence from Tanzania

Salvatore Di Falco, Brice Magdalou, David Masclet,

Marie Claire Villeval, Marc Willinger

\begin{abstract}
:
Embezzlement is a major concern. By means of a sequential dictator game, we investigate theoretically and experimentally whether making information more transparent and reducing the number of intermediaries in transfer chains can reduce embezzlement. Consistent with reference-dependent preferences in terms of moral ideal, we show that the impact of transparency is conditional on the length of the transfer chain and on the position of the intermediary in the chain. Its direct effect on image encourages honesty. Its indirect effect via expectations plays in the opposite direction, motivating intermediaries to embezzle more when expecting that the following intermediary will embezzle less.
\end{abstract}

Keywords:

Embezzlement, corruption, dishonesty, transparency, experiment

JEL codes:

C91, D73 


\title{
Can transparency of information reduce embezzlement? Experimental Evidence from Tanzania
}

\author{
Salvatore Di Falco ${ }^{\mathrm{a}}$, Brice Magdalou ${ }^{\mathrm{b}}$, David Masclet ${ }^{\mathrm{c}}$, \\ Marie Claire Villeval ${ }^{\mathrm{d}}$, Marc Willinger ${ }^{\mathrm{b}}$
}

\begin{abstract}
Embezzlement is a major concern. By means of a sequential dictator game, we investigate theoretically and experimentally whether making information more transparent and reducing the number of intermediaries in transfer chains can reduce embezzlement. Consistent with reference-dependent preferences in terms of moral ideal, we show that the impact of transparency is conditional on the length of the transfer chain and on the position of the intermediary in the chain. Its direct effect on image encourages honesty. Its indirect effect via expectations plays in the opposite direction, motivating intermediaries to embezzle more when expecting that the following intermediary will embezzle less.
\end{abstract}

JEL Codes: C91, D73

Keywords: Embezzlement, corruption, dishonesty, transparency, experiment

a University of Geneva, Bd du Pont-d'Arve 40, CH-1211 Genève 4, Suisse; Email: salvatore.difalco@unige.ch.

${ }^{\mathrm{b}}$ University of Montpellier, LAMETA, avenue Raymond Dugrand - Site Richter C.S. 79606, F34960 Montpellier Cedex 2, France. E-mail: brice.magdalou@umontpellier.fr, marc.willinger@umontpellier.fr.

${ }^{c}$ CREM, CNRS, University of Rennes, 7 place Hoche, 35000 Rennes, France, and CIRANO, Montreal. E-mail: david.masclet@univ-rennes1.fr.

${ }^{\mathrm{d}}$ Univ Lyon, CNRS, GATE UMR 5824, F-69130 Ecully, France ; IZA, Bonn; Department of Public Finance, University of Innsbruck. GATE: Ecully, France. E-mail: villeval@ gate.cnrs.fr

Acknowledgments: We are grateful to A. Angelsen, G. Attanasi, A. Barr, E. Bulte, L. Butera, G. Charness, M. Dufwenberg, C. Fluet, U. Gneezy, J. Hella, D. Houser, R. Lokina, T. Palfrey and participants at seminars at BETA Strasbourg, European University Institute in Florence, GATE Lyon, the HOME General Directorate at the European Commission in Brussels, ICES at George Mason University, Laval University in Quebec, London School of Economics, Oxford University, University of Maastricht, Wageningen University, and at the IMEBESS conference in Toulouse, the ASFEE conference in Paris, the ESA world meeting in Sydney, the SPI conference at the University of Chicago, and the workshop in behavioral economics at the University of California at Santa Barbara for useful comments. Financial support from the FELIS program of the French National Agency for Research (ANR-14-CE280010-01) is gratefully acknowledged. This research was performed within the framework of the LABEX CORTEX (ANR-11-LABX-0042) of Université de Lyon, within the program Investissements d'Avenir (ANR-11-IDEX-007) operated by the French National Research Agency (ANR). 


\section{Introduction}

Embezzlement is one of the many forms of corruption besides bribing and extortion. It corresponds to an intentional dishonest act, committed by individuals who misappropriate assets that were entrusted to them in order to monopolize or to steal them. ${ }^{1}$ Press releases regularly illustrate embezzlement by politicians, artists, or even ecclesiastics. ${ }^{2}$ Embezzlement is a worldwide scourge that is particularly worrying in developing countries because it generates inefficiency and unfairness (Bardhan, 1997; Fantaye, 2004; Fan et al., 2010; Olken and Pande, 2011). ${ }^{3}$ In 2013, the African Development Bank reported that during a 30-year time span embezzlement represents about US\$1.2 trillion in real terms. It is a particularly severe concern for charitable giving and international aid. Indeed, senders need to rely on intermediaries to distribute funds to recipients or to undertake development programs. This creates a favorable context for embezzlement because beneficiaries usually ignore the amount of the initial donations and the senders cannot verify the amounts that eventually go to the beneficiaries. ${ }^{4}$ This raises an issue both for transparency and for the organization of the transfer chain.

Despite its importance, embezzlement has received little attention in economics compared to the large literature on bribing (e.g., Rose-Ackerman, 1975; Shleifer and Vishny, 1993; Abbink et al., 2002; Bertrand et al., 2007; Olken, 2007; Cameron et al., 2009; Barr and Serra, 2010; Vicente, 2010; Armantier and Boly, 2011, 2012; Abbink and Serra, 2012; Banerjee et al., 2012;

\footnotetext{
${ }^{1}$ Embezzlement can use several techniques such as falsification of records, emission of false bills, declaration of ghost employees or stealing money in cash. In political science, Green (1993) defines embezzlement as a "theftafter-trust offense".

${ }^{2}$ Lady Gaga was sued over US\$5 millions for the proceeds of the sales of her charity bracelet "We Pray for Japan" to help the 2011 Tsunami victims. Not all of the proceeds went to Japan according to the legal network 1-800-LAWFIRM (Washington Post). In 2014, Cardinal Bertone, former Secretary of State of Vatican, was suspected of embezzlement for over 15 million Euros from Vatican accounts.

${ }^{3}$ For instance, under the reign of Mubutu (DR Congo) theft of overseas aid money or resource rents was estimated over US\$ 4 billion. US\$1.8 million given to Sierra Leone by the Department for International Development to support peacekeeping disappeared. Uganda spent $20 \%$ of its public expenditures on education in the mid 90 s but schools received only $13 \%$ of the government spending on the program; $20 \%$ of teachers' salaries in 1993 paid to ghosts (Reinikka and Svenson, 2004). After the 2010 earthquake the charity Yele Haiti gathered over US\$16 million in donations, but less than $1 / 3$ was distributed to emergency relief for Haitians.

${ }^{4}$ It should be noted, however, that in recent years donors can find more easily information about charities' efficiency thanks to on-line providers of comparative information such as Charity Navigator or Charity Watch.
} 
Serra and Wantchekon, 2012; Banuri and Eckel, 2015; Gneezy et al., 2015; Sequeira, 2016). Although both forms of corruption can be represented by a sequential three (or more)-player game, a major difference is that bribing always involves joint dishonesty between several players, which is not necessarily the case with embezzlement.

In this paper we study the embezzlement of senders' donations by intermediaries and its consequences on senders' behavior and recipients' welfare. We rely on a behavioral model and an experiment to address two key issues: (i) to what extent does transparency on senders' generosity for recipients reduce embezzlement, and (ii) how is embezzlement influenced by the structure of the transfer chain between senders and beneficiaries. We also investigate whether the impact of transparency is conditional on the length of the transfer chain. Indeed, adding more links increases both the number of intermediaries in a position to steal and the opportunity to dismiss suspicions of fraud onto other links. Thus, increasing transparency may not be so effective in longer transfer chains.

Our contribution is threefold. First, we contribute to the vast literature on dishonesty (Gneezy, 2005; Mazar et al., 2008; Fischbacher and Föllmi-Heusi, 2013; Abeler et al., 2014; Irlenbusch and Villeval, 2015) by complementing the rare previous studies on intermediaries' dishonesty and its consequences on receivers or donors. ${ }^{5}$ Comparing charitable giving with and without intermediaries using a within-subject design, Chlaß et al. (2015) found that most senders are either price-oriented (i.e., they donate less in the presence of intermediaries because embezzlement raises the implicit price of giving) or donation-oriented (i.e., they donate the same amount with intermediaries than without), rather than outcome-oriented (i.e., they increase their donation to compensate for expected embezzlement). Beekman et al. (2014) found that when

\footnotetext{
${ }^{5}$ The presence of intermediaries is usually associated to increased corruption. Drugov et al. (2014) show that by facilitating the relationship between a briber and a bribee, intermediaries intensify corruption by lowering its moral cost (see also Hasker and Okten, 2008). On the other hand, modeling embezzlement as a substitute for efficiency wages, Fan et al. (2010) sustain that tolerating embezzlement helps better fight bribery.
} 
local chiefs embezzle more resources, villagers are less likely to contribute to local public goods. Although we also consider the impact of embezzlement on senders' generosity and on recipients' welfare, our main contribution lies in the analysis of intermediaries' behavior. ${ }^{6}$

Second, we contribute to the analysis of policy interventions on embezzlement. In an experimental study on service delivery in Ethiopia, Barr et al. (2009) found less embezzlement when the wages of intermediaries or the monitoring probability were higher, and when monitors were elected rather than randomly selected. We consider alternative interventions, such as a shortening of the transfer chain. ${ }^{7}$ We also contribute to the expanding (and mixed) literature on the relationship between transparency and the performance of institutions (Azfar and Nelson, 2007; Olken, 2007; Kolstad and Wiig, 2009; Reinnika and Svenson, 2004, 2011) by exploring whether the impact of more transparent information on donations for recipients depends on the organization of the transfer chain. Olken (2006) show the importance of local monitoring but Platteau (2004) and Abbink and Ellmann (2010) find that observability may not deter embezzlement if intermediaries can select the beneficiaries of aid, as potential beneficiaries may withhold complaints against dishonest intermediaries to avoid the risk of not being selected. We remove this effect, as here intermediaries cannot choose among recipients.

Third, we contribute to the literature on how pro-social preferences are shaped by uncertainty in dictator games. Uncertainty is usually considered either on the side of the sender (Dana et al., 2007; Winschel and Zahn, 2014) or on the side of the receiver (Rapoport and Sundali, 1996; Huck, 1999; Güth et al., 1996). Introducing intermediaries and manipulating information allow us to consider the impact of uncertainty on both sides in the same study.

\footnotetext{
${ }^{6}$ Banerjee et al. (2015) also propose a game of embezzlement but their game is based on misreporting and they study whether embezzlement is higher for public sector aspirants than private sector applicants.

${ }^{7}$ Makowski and Wang (2015) observe that the embezzlement rate increases in the number of layers in the structure of transfers; in contrast to us, however, they use a common pool resource game in which withdrawals may not be characterized as a dishonest action.
} 
To address our questions, we have designed and conducted an experiment based on a Baseline treatment and a 2x2 factorial design. Our baseline treatment is a standard dictator game. Our remaining treatments are based on an embezzlement game that consists of a modified sequential dictator game with intermediaries. The dictator is a well-endowed sender, A, who can make a transfer to a poorly endowed recipient, C. Except in our Baseline, the transfer cannot be carried out directly but requires passing through intermediaries, B. ${ }^{8}$ Along one dimension, we vary the number of intermediaries $(0,1$ or 2$)$ in different between-subject treatments to investigate how the presence and the number of intermediaries affect both the senders' donations and the amounts actually received by the recipients. Along the other dimension, we manipulate information in a way that allows the recipient to know the amount of the donation and therefore to learn the amount that has been embezzled by intermediaries. We introduce therefore a minimal notion of transparency. Although there is no risk of monetary sanction, on may reasonably argue that transparency may nevertheless lower embezzlement if it increases the intermediaries' moral cost of stealing by making embezzlement visible to the recipient, which may induce a feeling of shame.

Our experiment was conducted with students in two university campuses located in Dar-esSalaam and Manzimbu in Tanzania. Tanzania is a prime area to study embezzlement. It ranks 119 out of 175 countries in the corruption perception index and it scores 31 out of 100 (from 0 for very corrupted to 100 for very clean) (Transparency International, 2014). ${ }^{9}$ By involving

\footnotetext{
${ }^{8}$ Surprisingly, compared to the standard dictator game (Forsythe et al., 1994; Hoffman et al., 1994) one can find very few sequential dictator games in the literature. For example, in Bahr and Requate (2007) a player A divides a pie between himself and a player B who can then divide the rest with player C. Our game is different: player A decides on how to share his endowment with player $\mathrm{C}$, while the role of player $\mathrm{B}$ is to transfer this amount from $\mathrm{A}$ to $\mathrm{C}$. While formally B is in the position to share the amount received between him and the next player, it is made clear in the instructions that A wants B to transfer his donation to C.

${ }^{9}$ Many examples of embezzlement can be found in the country. To cite a recent one, an Ernst and Young's report mentions that in 2013 US\$1.3 million disappeared from a Norwegian funded WWF project, "Strengthening Capacity of Environmental Civil Society Organizations". For an analysis of corruption scandals in Tanzania, see Gray (2015).
} 
subjects from a country in which embezzlement is pervasive, we expect to observe embezzlement, such that we can study the efficacy of our treatment manipulations.

We confront our data to the predictions delivered by a full-fledged behavioral model. The key hypothesis is that senders and intermediaries trade off pecuniary gains and moral costs. The model introduces a concept of moral ideal for both the senders and the intermediaries. This moral ideal constitutes a reference point and deviating from it generates a feeling of loss, assuming reference-dependent preferences (e.g., Kahnemann and Tversky 1979, Köszegi and Rabin, 2006). Although compatible with notions of guilt and guilt from blame (Battigali and Dufwenberg, 2007), our model focuses on expectations about the next players' actions and not on beliefs about the extent to which the receiver will feel he has been let down by the transfer decision. We predict that senders make donations if they care enough about the recipient's welfare. The moral cost for deviating from the moral ideal is sensible to the length of the chain and to transparency, directly via observation and indirectly via expectations. We predict that embezzlement is larger and donations lower in long chains. Transparency should reduce embezzlement, because of shaming, and increase donations but it may be less effective in long chains since the feeling of shame is diluted.

Our results show evidence of embezzlement. Overall, the recipients are better off when the transfer chain is shorter both because senders are more generous when donations can be made more directly and because less intermediaries are in a position to embezzle (mechanical effect). Interestingly, however, at the individual level the mean percentage of the donation that is embezzled by an intermediary is lower in long chains than in short chains. Indeed, the first intermediaries in long chains embezzle a lower percentage than intermediaries in short chains. The second intermediaries embezzle the same percentage than intermediaries in short chains but this applies to smaller amounts because they are further down in the chain. This indicates that although they keep part of the donation for themselves, intermediaries care about the welfare of 
the recipients. The direct effect of transparency is to reduce embezzlement by making dishonesty observable but this effect can be seen only on intermediaries in short chains and on the second intermediaries in long chains. In contrast, the first intermediaries embezzle slightly more under transparency. A possible reason is that the direct effect of transparency is compensated by an indirect effect in the opposite direction; this indirect effect results from the expectation of less embezzlement further down in the chain, which should improve the recipient's welfare. These findings show that introducing more transparency does not necessarily increase the safety of transfers - at least in the absence of sanctioning institutions- and that the organization of the transfer chain should be taken into consideration.

The remainder of the paper is organized as follows. Section 2 describes our experimental strategy. Section 3 presents our behavioral model of embezzlement. Section 4 analyzes the results. Section 5 discusses these results and concludes.

\section{Experimental design and procedures}

\subsection{Experimental design}

Our experiment consists of a baseline condition using a dictator game without intermediary and a $2 \times 2$ factorial design in which we manipulate both the number of intermediaries and transparency. Each treatment is identified as \#-INT-T, where \# is the number of intermediaries $(0,1$ or 2$)$ and $\mathrm{T}$ (I or NI) accounts for transparency of information. All treatments implement a one-shot zero-sum game, using a between-subject design. Let us describe first the Baseline.

The Baseline treatment (0-Int treatment, hereafter) is a dictator game involving a sender and a receiver, designated as "person A" and "person C" in the instructions (see Appendix 1). The sender receives an endowment of 15000 Tanzanian Shillings (TS), consisting of 15 bills of TS1000 each, and the recipient is endowed with TS2000. ${ }^{10}$ The sender has to decide how many

\footnotetext{
${ }^{10}$ In contrast with the standard dictator game, the receiver gets a positive endowment to avoid null payoffs that could exaggerate the amount of transfers and be less realistic. The structure of the game is unaffected by this choice.
} 
bills he is willing to transfer to the recipient. Let us call this transfer the "donation" in the rest of the paper. The recipient is passive.

In the four other treatments, we introduce sequentiality in the dictator game by placing either one or two intermediaries between the sender and the recipient. Our aim is to test whether the length of the transfer chain affects $i$ ) the extent of embezzlement at the aggregate and at the individual levels, and ii) the amount of the donations. In the instructions the intermediary is designated as "person B" and in case of multiple intermediaries as "person B1" or "person B2" depending on the order in the transfer chain. Each intermediary receives an endowment of TS5000 to keep. In the 1-Int-NI treatment, the sender's donation transits through a single intermediary; in the 2-Int-NI treatment, the sender's donation transits through two consecutive intermediaries. This mimics the situation of a sender in a developed country making a donation to a beneficiary in a developing country; the donation is collected by an organization that will transfer it to a local representative. In our instructions, the intermediaries are told explicitly that their role is "to transfer the money to person C" and that they are not allowed to transfer a fraction of their own endowment to the recipient. By indicating that the envelope contains the TS "that the person A you are matched with wants you to transfer to person C', it is made clear to the subjects that if they do not transfer all the money to the next player they do not respect A's intentions. ${ }^{11}$ Therefore, while formally B is in the position to share the amount received between him and the next player (like a dictator), it is made clear in the instructions that A wants B to transfer his donation to $\mathrm{C}$.

\footnotetext{
${ }^{11}$ Our design differs substantially from that of Chlaß et al. (2015) who opted for a non-neutral language (using the notions of donor and charitable institution) and who measure embezzlement by the amount charged to the donor in administration costs. In their game, the charitable institution chooses how much of the donor's donation to allocate to supplementary administration costs and how much to pass on to the recipient. Their instructions made it therefore explicit that the intermediary was entitled to make an allocation decision between himself and the recipient. In our instructions, we ask intermediaries to count the money in their two envelopes (see procedures) and decide how much they leave in the envelope to transfer. A further difference is that decisions in their game were made simultaneously while in our case they were made sequentially.
} 
In the 1-Int-NI and 2-Int-NI treatments uncertainty is important, as the sender ignores the amount actually received by the recipient, the second intermediary ignores how much the first intermediary initially received, and the recipient ignores how much money was initially sent to him. ${ }^{12,13}$ The informational structure of the 1-Int-I and 2-Int-I treatments is similar, for one exception: the recipient is now informed about the amount of the sender's donation and this is made common knowledge to all players. Our aim is testing whether making the recipient aware of the amount donated by the sender (and thereby about the total amount embezzled) affects $i$ ) the extent of embezzlement at the aggregate and at the individual levels, and ii) the amounts donated. By manipulating both transparency and the length of the transfer chain, we can test whether the impact of transparency on embezzlement depends on the length of the transfer chain. Note that in none of our treatments intermediaries face a risk of monetary sanction. Therefore, all the expected effects can only be driven by internalized moral considerations.

In the final part of the experiment, a questionnaire elicits risk and time preferences. ${ }^{14}$ Payment for answering this questionnaire was conditional on tossing a coin in private, like in Bucciol and Piovesan (2011) or Abeler et al. (2014). Subjects were instructed to toss the coin that was put on their table as many times as they wanted but they were asked to report only the outcome of the first toss. Reporting head paid TS2000, reporting tail paid nothing. This task gives us a simple measure of dishonesty in our subject-pool when social preferences do not come into play (in contrast to the game where money is taken from another participant).

\footnotetext{
${ }^{12}$ We do not to let the second intermediary learn about the first intermediary's decision to avoid any peer effect in the design. Studying peer effects in transfer chains would be interesting in itself but we leave it for further research. In addition, in real settings it is not unlikely that intermediaries cannot observe the behavior of other intermediaries acting before them.

${ }^{13}$ We also decided not to elicit beliefs during the experiments to avoid both hedging problems and focusing the subjects' attention on potential stealing.

${ }^{14}$ Like Dohmen et al. (2011), subjects were asked: "Are you generally a person who is fully willing to take risks or do you try to avoid taking risks?". Following Visher et al. (2013), they were also asked: “Are you generally an impatient person, or someone who always shows great patience?". They had to report how they see themselves on a scale graduated from 0 to 10 from trying to avoid taking risks (or being very impatient) to being fully prepared to take risks (or being very patient).
} 


\subsection{Procedures}

The experiment was conducted in Tanzania on the campuses of the University of Dar-es-Salaam and Sokoine University of Agriculture in Mazimbu. These are the two biggest universities in the country, providing education on a wide range of subjects (including science, agriculture, business, planning). The aim was to diversify the origin of the subjects, one university being located in the country's largest city and the other one in a rural area. The choice of Tanzania was motivated by the high rate of corruption in the country. Consistently, our coin task indicates a very high cheating rate: $91.02 \%$ of the subjects reported heads, which differs significantly from 50\% (binomial test: $p<0.001) .{ }^{15}$ In comparison, the subjects in Abeler et al. (2012) reported a percentage of wining outcomes that did not differ from $50 \%$. This indicates that the norm of honesty is low in our pool of subjects.

1080 students were recruited (540 on each campus) via announcements on the bulletin board system and in teaching buildings. Each of ten sessions involved between 90 and 120 subjects, depending on the treatment. Table 1 provides summary statistics for the sessions and the subjects' main characteristics. The null hypothesis of equal characteristics across locations is rejected for several variables. It is thus crucial to control for these variables in our analysis.

Table 1. Comparison of the two subject pools

\begin{tabular}{llll}
\hline Location & Dar-es-Salaam & Mazimbu & Total \\
\hline Characteristics of sessions & & & \\
Treatments & Nb subjects & Nb subjects & Nb subjects (Nb groups) \\
0-Int & 100 & 100 & $200(100)$ \\
1-Int-NI & 90 & 90 & $180(60)$ \\
1-Int-I & 90 & 90 & $180(60)$ \\
2-Int-NI & 120 & 120 & $240(60)$ \\
2-Int-I & 120 & 120 & $240(60)$ \\
Total & 540 & 540 & $1080(340)$ \\
\hline Characteristics of subjects & & & -values \\
Male & $65.65 \%$ & $75.55 \%$ & $<0.001^{\mathrm{a}}$ \\
\hline
\end{tabular}

\footnotetext{
${ }^{15}$ Reports could have been affected by the outcome of the previous game. However, if the intermediaries report significantly more frequently head than the senders (proportion test: $p=0.093$ ), no other pairwise comparison indicates significant differences. Since we cannot observe honesty at the individual level, we do not include this variable in the regression analysis.
} 


\begin{tabular}{llll}
\hline Age & $22.27(2.37)$ & $22.89(3.21)$ & $0.003^{\mathrm{b}}$ \\
Married & $4.27 \%$ & $8.16 \%$ & $0.001^{\mathrm{a}}$ \\
Christian & $83.15 \%$ & $83.30 \%$ & $0.946^{\mathrm{a}}$ \\
Muslim & $15 \%$ & $15.40 \%$ & $0.855^{\mathrm{a}}$ \\
Religious practice (1 to 5) & $4.09(1.05)$ & $4.15(1.03)$ & $0.416^{\mathrm{b}}$ \\
Low family wealth & $15.93 \%$ & $27.59 \%$ & $<0.001^{\mathrm{b}}$ \\
Patience (from 0 to 10) & $7.88(2.88)$ & $7.99(3.03)$ & $0.059^{\mathrm{b}}$ \\
Risk lover (from 0 to 10) & $7.24(3.34)$ & $7.66(3.30)$ & $0.006^{\mathrm{b}}$ \\
\hline
\end{tabular}

Note: ${ }^{\mathrm{a}}$ indicates proportion tests and ${ }^{\mathrm{b}}$ Mann-Whitney tests in which one subject gives one independent observation. Religious practice is coded 1 for "never pray", 2 for "pray rarely", 3 for "pray every week", 4 for "pray once per day", and 5 for "pray several times per day". Family wealth is assessed through the answer to the question: "If you compare your family's economic conditions to the others in your hometown, your family is: very poor / poor / average / rich / very rich." "Low family wealth" is equal to 1 if the response is "very poor" and "poor" and 0 otherwise.

Upon arrival, subjects were seated in a large aula and received the instructions for all roles in both Swahili and English. This assured that all the details about roles and payoffs were common knowledge. The instructions were read aloud and questions were answered in private. Then, subjects were split randomly into 2, 3 or 4 separate and non-contiguous rooms, depending on the treatment, with each room corresponding to a different role. We instructed subjects not to talk with anyone while proceeding to their room and this was strictly enforced. In the room, several seats isolated each subject from his neighbors in order to avoid communication and scrutiny (see Appendix 2). Once all the subjects were seated, they discovered which role was assigned to the subjects. Then, they were given some time to read again the instructions. Each subject received a random group identification number matching each person $\mathrm{A}$ with a person $\mathrm{C}$ and, according to the treatment, zero, one or two persons B.

To avoid scrutiny, we used opaque bags to transfer the money and for the subjects to make their decision secretly (see Appendix 2). Each sender received a bag containing two envelopes: a white envelope containing 15 bills of TS1000 and a brown envelope that was empty. The brown envelope could be used to send money to the recipient and it had to be kept in the bag. The senders had to decide how many bills to move from the white to the brown envelope. Subjects were instructed to make their transfer - if any- within the bag so that their decision could not be observed by anyone. Then, assistants collected the bags and brought them to a separate room where the content of the brown envelope was recorded under the supervision of the 
experimentalist. Then, assistants distributed the bags containing the brown envelope to the recipients in treatment 0 -Int or to each matching intermediary in the other treatments, after adding a white envelope containing the endowment of the next player (five bills for an intermediary or two bills for the recipient). The intermediaries were instructed to count the content of their white and their brown envelopes within the bag and to take out the white envelope for them to keep. At this precise moment, they had an opportunity to move bills from the brown envelope containing the donation to their white envelope. They were also told that they could not put their own bills in the brown envelope. A similar procedure was implemented in the case of two intermediaries. Finally, after assistants had collected the bags, the content of the brown envelopes was again recorded in a separate room. ${ }^{16}$ After adding a new white envelope to the brown envelope, the bags were brought to the recipients' room.

Once the bags were collected, we administered the final questionnaire. In contrast to the other players, the recipients filled out their questionnaire before receiving their bag since they had nothing to do than wait for others' decisions. Then, subjects had to report the toss of the coin to determine additional payment. We were careful to dismiss the subjects in the different rooms at different moments so that they could not meet each other. The experiment lasted about 1.5 hour. Earnings averaged at TS11330. ${ }^{17}$

\section{A behavioral model of embezzlement}

We first introduce the framework of the model before stating the role of moral ideal and beliefs. Then, we examine the impact of both information transparency and the number of intermediaries on donations and embezzlement. Finally, we summarize our predictions.

\footnotetext{
${ }^{16}$ We did not use a double blind procedure; thus, subjects may have anticipated that their decision was recorded. Note that we are not interested in making point predictions about the extent of embezzlement in real settings. We are interested in studying treatment effects.

${ }^{17}$ In Tanzania, the average wage in the private sector is TS78000 per month - about US $\$ 45$.
} 


\subsection{The framework}

We model the embezzlement context as a modified sequential dictator game. The game consists in a sender (player 0) and a population of $n$ intermediaries (player 1 to player $n$ ) who decide, sequentially, to transfer a fraction of the amount received from the previous player, to the following player in the chain. The amount received by player $i$ is denoted by $r_{i}$, normalizing the amount initially received by the sender to $r_{0}=1$. At the end of the chain, the amount is transferred to a last player, called the recipient. We emphasize that the game is a modified sequential dictator game in the sense that the explicit and common information role of the intermediaries is to transfer the money received from the sender to the recipient, without adding money from his own endowment. Hence, different moral obligations may intervene for senders and intermediaries.

In the game, player $i$ transfers a fraction $\sigma_{i} \in[0,1]$ of the amount $r_{i}$ she receives, and keeps for herself the fraction $\left(1-\sigma_{i}\right)$ which is referred, for all the players but the sender, as her relative embezzlement. One observes that the amount $r_{i}$ received by player $i$ is such that $r_{1}=\sigma_{0}, r_{2}=$ $\sigma_{0} \sigma_{1}$ and, more generally, $r_{i}=\prod_{j=0}^{i-1} \sigma_{j}$. We also denote by $\varphi_{i}=\prod_{j=i+1}^{n} \sigma_{j}$ the total fraction of player $i$ 's transfer that really goes to the recipient. Equivalently, $\left(1-\varphi_{i}\right)$ represents the total relative embezzlement of all the players after player $i$. The total relative embezzlement is therefore $\left(1-\varphi_{0}\right)$, namely the fraction of the sender's donation embezzled at the end of the chain. In the standard dictator game (our Baseline) where there are only two players (the sender and the recipient), $\varphi_{0}=1$.

Player $i$ knows the amount $r_{i}$ she receives (which is private information) and she forms beliefs about the total fraction $\varphi_{i}$ of the amount she transfers that eventually reaches the recipient. We assume that these beliefs can be affected by a parameter $\theta \in\{0,1\}$ reflecting transparency in the game. We define transparency as a situation where the recipient observes, under common 
knowledge, the initial donation of the sender. We let $\theta=1$ under transparency, and $\theta=0$ otherwise. Finally, we denote by $\bar{\varphi}_{i}(\theta)$ the total fraction of player $i$ 's transfer she expects the recipient will receive under $\theta$.

Under the assumption of standard selfish preferences, a sender keeps the whole amount received for herself and therefore intermediaries have no opportunity to embezzle. Our behavioral model considers instead that individuals have a moral motivation for giving (sender) or transferring (intermediaries). We assume that player $i$ 's utility function has the following additive separable form:

$$
U\left(\sigma_{i}, r_{i}, \bar{\varphi}_{i}(\theta), \theta\right)=u\left(\left(1-\sigma_{i}\right) r_{i}\right)+f\left(\sigma_{i}, \bar{\varphi}_{i}(\theta), \theta\right)
$$

where $u$ represents the player's material utility and $f$ her social utility. $u$ depends on her monetary payoff $\left(1-\sigma_{i}\right) r_{i}$, or equivalently on the fraction of the money received that she keeps for herself. ${ }^{18} f$ captures the player's moral motivation for giving or transferring, depending on her role.

Hypothesis 1. The function $u$ is strictly increasing and concave $\left(u_{1}>0\right.$ and $\left.u_{11}<0\right)$.

We then assume that player $i$ is characterized by a moral ideal that constitutes a reference point in terms of donation/transfer, denoted $\hat{\sigma}_{i}$. Given $\theta$ and $\bar{\varphi}_{i}(\theta)$, the social utility $f$ increases with the donation/transfer as long as $\sigma_{i} \leq \hat{\sigma}_{i}$ and is non-increasing beyond. This may be interpreted as moral loss aversion when the donation/transfer is lower than the reference point. We also assume that $f$ is weakly concave in its first argument.

Hypothesis 2. There exists $\hat{\sigma}_{i} \in[0,1]$ such that $f_{1}\left(\sigma_{i},,^{\prime}\right)>0$ for all $\sigma_{i}<\hat{\sigma}_{i}$, and $f_{1}\left(\sigma_{i},,^{\prime}\right) \leq 0$ for all $\sigma_{i}>\hat{\sigma}_{i}$. Moreover $f_{11} \leq 0$.

Hypothesis 2 is compatible with many specifications, most of which have been discussed in the literature on social preferences (see Appendix 3).

\footnotetext{
${ }^{18}$ Note that we assume, without loss of generality, that there is no initial endowment for the players other than the sender.
} 
We emphasize that we model the senders' and intermediaries' preferences in a similar fashion. Nevertheless, it can be considered that the moral motives of giving or transferring are different, respectively, for senders and intermediaries. Indeed, the sender's donation relies on a concern for the recipient's well-being, or on warm-glow from giving. In contrast, the intermediary's decision is more likely grounded, either on the avoidance of the negative moral inclination that leads to embezzlement, or on the warm-glow from behaving honestly. Although hypotheses 1 and 2 can be reasonably assumed for the preferences of all the players, the social utility $f$ can differ between senders and intermediaries. ${ }^{19}$

\subsection{Impact of the moral ideal and beliefs}

Assuming utility function (*) and hypotheses 1 and 2, proposition 1 states a preliminary result:

Proposition 1. For a player $i$, there exists a unique donation/transfer denoted $\sigma_{i}^{*}$ that maximizes her preferences, which is not higher than her moral ideal ideal $\hat{\sigma}_{i}$. A necessary and sufficient condition to have $\sigma_{i}^{*}$ strictly greater than zero is that, when $\sigma_{i}=0$, the marginal utility loss due to a diminution of the monetary payoff is more than compensated by the marginal increase in the social utility $f$.

A technical formulation of all propositions (including their proofs), is presented in Appendix 3 (for proposition 1, see propositions 1a and 1b).

The result stated by proposition 1 is true regardless of the player's beliefs about embezzlement after her in the chain, and regardless of the information condition. Hence, a player who anticipates full embezzlement after her $\left(\bar{\varphi}_{i}(\theta)=0\right)$, can nevertheless donate/transfer a positive amount of money to compensate the moral loss vis-à-vis the reference point. For the sender (the intermediary), this can be observed if she has an intrinsic motivation to give (behave honestly), independent of the amount eventually obtained by the recipient.

We now investigate the impact of the player's beliefs relative to embezzlement further down in the chain on her optimal donation/transfer. On the one hand, embezzlement can reduce the

\footnotetext{
${ }^{19}$ For instance, if stealing is blamed in the society, the reference level of transfer $\hat{\sigma}_{i}$ can be very high (close to 1 ) for an intermediary. On the contrary, it can be low for a sender, the transfer being a pure donation. For a more accurate presentation, we could replace $U$ by $U_{i}$ and $f$ by $f_{i}$ in the utility expression.
} 
motivation to donate/transfer because some money does not reach the recipient, and hence an increase in the anticipated embezzlement reduces her optimal donation/transfer. On the other hand, a player can be inclined to compensate anticipated embezzlement, in which case, an increase in anticipated embezzlement raises her optimal donation/transfer. Thus, the anticipated embezzlement may (or not) have an impact on a player's optimal donation/transfer. ${ }^{20}$ This is stated as proposition 2 .

Proposition 2. An increase in the anticipated embezzlement reduces [resp. increases, resp. has no impact on] the player's optimal donation/transfer if and only if $f_{12} \geq 0$ [resp. $f_{12} \leq 0$, resp. $\left.f_{12}=0\right]$.

Hence, a player donates/transfers less when she anticipates more embezzlement, if and only if the marginal social utility of her donation/transfer $\left(f_{1}\right)$ weakly increases in the fraction of her transfer that she expects the recipient will receive $\left(\bar{\varphi}_{i}(\theta)\right) .{ }^{21}$ Proposition 2 is useful to understand the effect of transparency and of the number of intermediaries on the player's behavior.

\subsection{Transparency and the number of intermediaries}

Because the recipient cannot be directly hurt by an unobservable embezzlement (he may believe that the sender was not generous), the moral cost of embezzling for the intermediaries is lower when there is no transparency of information $(\theta=0)$. There is actually a direct and an indirect effect of transparency on donations/transfers. The direct effect is that common knowledge of observability of donations by the recipient affects the amounts donated/transferred..$^{22}$ The

\footnotetext{
${ }^{20}$ In a comparable framework, Chlaß et al. (2015) describe the senders according to their reaction to embezzlement, on the basis of the following classification: price-oriented, outcome-oriented or donation-oriented.

${ }^{21}$ It is important to distinguish the impact of $\bar{\varphi}_{i}(\theta)$ on the optimal donation/transfer from its impact on utility. We can reasonably assume that a player prefers that intermediaries transfer higher fractions to the recipient. One immediately observes that the player's utility increases with the anticipated intermediaries' transfer if and only if $f_{2}>0$. But this condition is neither necessary nor sufficient to imply a modification of the player's optimal donation/transfer. For instance, if the utility function is such that $U\left(\sigma_{i}, r_{i}, \bar{\varphi}_{i}(\theta), \theta\right)=u\left(\left(1-\sigma_{i}\right) r_{i}\right)+\bar{\varphi}_{i}(\theta)$, utility increases with $\bar{\varphi}_{i}(\theta)$ but the optimal donation/transfer is independent from it.

${ }^{22}$ In the experiment and the treatment with transparency only the total embezzlement, by all the intermediaries, is known by the recipient (this is the difference between the amount donated by the sender, which is known, and the amount she receives from the last intermediary). Hence, while the sender's behavior is fully observed under transparency, it is fully observable for an intermediary if and only if she is the only intermediary in the chain.
} 
indirect effect goes through the impact on player's beliefs regarding the transfers of intermediaries after them in the chain. The indirect effect affects all the intermediaries in the chain except the last one who is affected only by the direct effect. Proposition 3 considers the direct effect, controlling for the indirect effect.

Proposition 3. Assume that transparency has no impact on the anticipated embezzlement. Then the optimal donation/transfer of a player weakly increases with transparency if and only if the marginal social utility of her donation/transfer also weakly increases with transparency $\left(f_{1}(\because,, 0) \leq f_{1}(\because, 1)\right)$.

Hence, a sender whose social utility function satisfies the condition of proposition 3 perceives transparency as a moral incentive to donate. For an intermediary, the same condition implies that transparency increases the moral cost of embezzling, as long as transparency does not affect his anticipated embezzlement. We now combine the direct and indirect effects of transparency. For senders or intermediaries, we assume the following two hypotheses:

Hypothesis 3. A player anticipates that transparency cannot increase embezzlement of all the intermediaries after her in the chain $\left(\bar{\varphi}_{i}(0) \leq \bar{\varphi}_{i}(1)\right)$.

Hypothesis 4. The direct effect of transparency increases in the donation/transfer $\left(f_{1}(\because, ;, 0) \leq\right.$ $f_{1}(\because, 1)$, as stated in proposition 3$)$.

Under hypotheses 3 and 4 we establish proposition 4, closely related to proposition 2.

Proposition 4. a) If $f_{12} \geq 0$, then transparency unambiguously increases the player's optimal donation/transfer. b) If $f_{12}<0$, then the impact of transparency on the player's optimal donation/transfer is ambiguous, unless the player is the last intermediary in the chain. In the latter case, transparency unambiguously increases the optimal transfer.

Proposition 4 is intuitive. If $f_{12} \geq 0$, the direct and the indirect effects of transparency both go in the same direction. Indeed, the player anticipates that transparency cannot increase embezzlement after her in the chain (hypothesis 3 ). Therefore, if $f_{12} \geq 0$, the donation/transfer increases (proposition 2, in a dual version). This indirect effect combines with the direct effect which is also positive by assumption (hypothesis 4). In contrast, if $f_{12}<0$, the direct and indirect effects go into opposite directions. 
We finally investigate the impact of the number of intermediaries on players' behavior. Assume the following hypothesis about beliefs:

Hypothesis 5. A player anticipates that an increase in the number of intermediaries cannot decrease embezzlement after her in the chain.

Proposition 5 is an immediate corollary of proposition 2, because the number of intermediaries only plays a role through the anticipated embezzlement.

Proposition 5. An increase in the number of intermediaries reduces [resp. increases, resp. has no impact on] the optimal donation/transfer if and only if $f_{12} \geq 0$ [resp. $f_{12} \leq 0$, resp. $f_{12}=0$ ].

\subsection{Predictions}

Based on propositions 1-5, we can now state precise predictions about players' actions in our experiment. We assume that all players are characterized by the utility function (*) which satisfies hypotheses $1-5$. As established by propositions 2,4 and 5 , the sign of $f_{12}$ determines the optimal donation/transfer and conditions the impact on players' behavior of their strategic environment (transparency, number of intermediaries, beliefs). We therefore introduce a further restriction on players' behavior, stated as hypothesis 6 .

Hypothesis 6. $f_{12}>0$ for senders and $f_{12}<0$ for intermediaries.

For a sender, hypothesis 6 means that an increase in anticipated embezzlement reduces her optimal donation (see proposition 2): Embezzlement is perceived as the price to pay for donating, and therefore any price lowers donations (see Chlaß et al., 2015). For an intermediary, we assume the opposite: An increase in anticipated embezzlement after her in the chain increases the moral cost of her own embezzlement, and thus increases her transfer. This can be interpreted in terms of guilt for example: if the first intermediary anticipates that the receiver expects to receive a certain amount and that the next intermediary in the chain will embezzle a fraction of the donation, he may limit his own embezzlement to avoid that the receiver feels excessively 
disappointed. Under hypotheses 1-6, we can derive the following predictions from propositions 1-5:

Predictions for the senders' donations. P1: A sender donates a strictly positive amount to the recipient. P2: For a given level of information, the length of the chain decreases the donation. P3: For a given number of intermediaries, transparency increases the donation.

Predictions for intermediaries' transfers. P4: An intermediary transfers a strictly positive amount to the next player. P5: For a given level of information, the length of the chain decreases the first intermediary's embezzlement. P6: For a given number of intermediaries, transparency has an ambiguous effect on the first intermediary's embezzlement, but implies lower embezzlement for the last intermediary in the chain.

\section{Results}

We start by comparing the recipients' earnings under the various transfer regimes. We next investigate the impact of the number of intermediaries and of transparency first, on donations, and second, on embezzlement.

\subsection{Recipients' earnings}

Our first result is stated as follows:

Result 1 (Recipients earnings) a) The mean amount actually received by the recipients decreases in the number of intermediaries. b) Transparency has no impact on this amount.

Support for Result 1. Table 2 provides summary statistics for each treatment. It notably indicates for the recipients the mean amount received, the percentage of the sender's endowment and the percentage of the donation received, and the mean final earnings. Figure 1 complements Table 2 by displaying the mean amount received by a recipient, by treatment. 


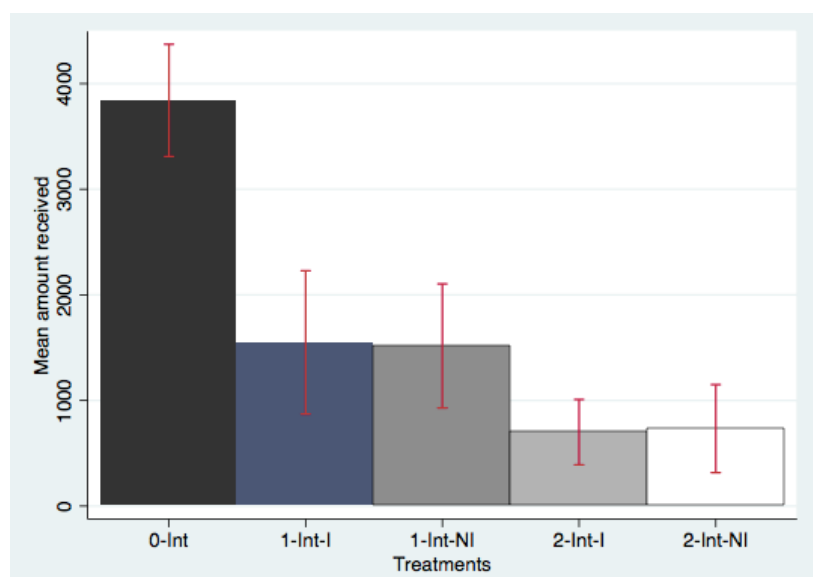

Figure 1. Mean amount actually received by the recipients, by treatment

Table 2. Summary statistics

\begin{tabular}{|c|c|c|c|c|c|}
\hline & 0-Int & 1-Int-I & 1-Int-NI & 2-Int-I & 2-Int-NI \\
\hline \multicolumn{6}{|l|}{ Recipients } \\
\hline Mean amount received & 3841.67 & 1550 & 1516.67 & 700 & 733.33 \\
\hline $\begin{array}{l}\text { Mean percentage received from } \\
\text { the sender's endowment }\end{array}$ & 25.61 & 10.33 & 10.11 & 4.67 & 4.89 \\
\hline $\begin{array}{l}\text { Mean percentage received from } \\
\text { the donation }\end{array}$ & 100 & 49.45 & 37.96 & 28.23 & 25.12 \\
\hline Mean final payoff & 5841.67 & 3550 & 3516.67 & 2700 & 2733.33 \\
\hline \multicolumn{6}{|l|}{ Intermediaries } \\
\hline Mean total amount embezzled & & 2925 & 2200 & 1862.74 & 2979.59 \\
\hline Mean total percent. embezzled & & 50.55 & 62.04 & 71.76 & 74.88 \\
\hline \multicolumn{6}{|l|}{ - Intermediary 1} \\
\hline Mean amount embezzled & - & 2925 & 2200 & 1176.47 & 1326.53 \\
\hline Mean percent. embezzled & - & 50.55 & 62.04 & 44.78 & 39.79 \\
\hline Mean final payoff & - & 6950 & 6833.33 & 6000 & 6083.33 \\
\hline \multicolumn{6}{|l|}{ - Intermediary 2} \\
\hline Mean amount embezzled & - & - & - & 897.44 & 2314.29 \\
\hline Mean percent. embezzled & - & - & - & 52.14 & 60.69 \\
\hline Mean final payoff & - & - & - & 5583.33 & 6350 \\
\hline \multicolumn{6}{|l|}{ Senders } \\
\hline Mean amount donated & 3841.67 & 3500 & 3350 & 2283.33 & 3166.67 \\
\hline Mean percent. donated & 25.61 & 23.33 & 22.33 & 15.22 & 21.11 \\
\hline Mean final payoff & 11158.33 & 11500 & 11650 & 12716.67 & 11833.33 \\
\hline
\end{tabular}

Notes: The mean amounts donated include donations equal to 0 . The mean amounts embezzled and the percentages embezzled are conditional on receiving a positive amount from the previous player. "Mean percent. received from the sender's endowment" corresponds to the amount received*100/15000. "Mean percent. received from the donation" corresponds to the amount received*100/amount donated by the sender. "Mean percent. embezzled" corresponds to the amount not transferred*100/amount received from the previous player.

Both Figure 1 and Table 2 indicate that compared to the 0-Int treatment, the presence of a single intermediary lowers by $60.09 \%$ the mean amount actually received by the recipient. Furthermore, introducing a second intermediary decreases this amount by another $53.26 \%$ (for a total decrease of $81.34 \%$ compared to the 0 -Int treatment). Mann-Whitney tests (M-W, hereafter) indicate that the amount actually received is significantly lower in each treatment with 
intermediary compared to 0 -Int $(p<0.001) .{ }^{23}$ This amount is also significantly lower in 2-Int-NI than in 1-Int-NI (M-W: $p=0.069)$ and lower in 2-Int-I than in 1-Int-I (M-W: $p=0.049)$; however, the distribution does not differ significantly (K-S: $p=0.378$ and $p=0.182$, respectively). In contrast, transparency does not affect significantly the amount received ( $p=0.817$ with one intermediary and $p=0.762$ with two intermediaries).

To provide further support for Result 1, we ran estimates on the amount actually received by the recipient. Table 3 reports the marginal effects from four Tobit regressions accounting for left-censored data. Standard errors are clustered at the matched group level. In model (1), the independent variables include dummy variables for each treatment with 0-Int taken as the reference category, and a control for the experimental location. Model (2) is similar to (1), except that we control for the amount donated. Models (3) and (4) replicate models (1) and (2), respectively, after excluding the dictator game with 1-Int-I as the reference. ${ }^{24}$

Table 3. Amount received by the recipient

\begin{tabular}{|c|c|c|c|c|}
\hline \multirow{2}{*}{ Dependent variable } & \multicolumn{4}{|c|}{ Absolute amount received } \\
\hline & (1) & (2) & (3) & (4) \\
\hline $0-$ Int & Ref. & Ref. & & \\
\hline 1-Int-I treatment & $\begin{array}{c}-1190.692 * * * \\
(171.37)\end{array}$ & $\begin{array}{c}-1165.452 * * * \\
(112.06)\end{array}$ & Ref. & Ref. \\
\hline 1-Int-NI treatment & $\begin{array}{c}-1263.987 * * * \\
(164.43)\end{array}$ & $\begin{array}{c}-1136.980 * * * \\
(98.281)\end{array}$ & $\begin{array}{c}-90.308 \\
(241)\end{array}$ & $\begin{array}{l}-4.327 \\
(178.2)\end{array}$ \\
\hline 2-Int-I treatment & $\begin{array}{c}-1594.189 * * * \\
(150.37)\end{array}$ & $\begin{array}{c}-1207.739 * * * \\
(100.46)\end{array}$ & $\begin{array}{c}-469.703 * * \\
(222.57)\end{array}$ & $\begin{array}{c}-114.336 \\
(173)\end{array}$ \\
\hline 2-Int-NI treatment & $\begin{array}{c}-1647.304 * * * \\
(151.81)\end{array}$ & $\begin{array}{c}-1475.182 * * * \\
(102.75)\end{array}$ & $\begin{array}{c}-538.338 * * \\
(224.49)\end{array}$ & $\begin{array}{c}-400.481^{* *} \\
(175.2)\end{array}$ \\
\hline Dar-es-Salaam & $\begin{array}{c}-709.426^{* * * *} \\
(162.54)\end{array}$ & $\begin{array}{c}-716.200 * * * \\
(116.69)\end{array}$ & $\begin{array}{c}-583.346 * * * \\
(166.47)\end{array}$ & $\begin{array}{l}-704.467 * * * \\
(130.28)\end{array}$ \\
\hline $\begin{array}{l}\text { Amount initially sent } \\
\text { by the sender }\end{array}$ & - & $\begin{array}{c}0.370 * * * \\
(0.046)\end{array}$ & - & $\begin{array}{c}0.217 * * * \\
(0.037) \\
\end{array}$ \\
\hline $\mathrm{Nb}$ of observations & 360 & 360 & 240 & 240 \\
\hline Left censored observations & 147 & 147 & 137 & 137 \\
\hline Log pseudo-likelihood & -2120.459 & -1999.577 & -1069.691 & -1025.626 \\
\hline
\end{tabular}

Notes: Table 3 reports marginal effects from Tobit estimates. Robust standard errors are clustered at the matched group level. ***, $* *$, and $*$ indicate significance at the $0.01,0.05$, and 0.10 level, respectively.

\footnotetext{
${ }^{23}$ In the rest of the section, unless specified otherwise all the non-parametric statistics are based on two-tailed MannWhitney tests in which each subject gives one independent observation. We have also conducted Kolmogorov Smirnov tests (K-S, hereafter). Most of the time they deliver the same conclusions as the M-W tests.

${ }^{24}$ We take 1-Int-I as the reference category for the sake of consistency with models (1) and (2) where the reference is the baseline dictator game in which, by definition, the donation is visible to the recipient.
} 
Model (1) confirms that introducing one intermediary decreases significantly the amount received by TS1190.69 with transparency and by TS1263.99 without. Introducing two intermediaries decreases this amount by TS1594.19 with transparency, and by TS1647.30 without. The coefficients of 1 -Int-NI and 2-Int-NI differ significantly ( $p=0.043$ ), as well as the coefficients of 1-Int-I and 2-Int-I ( $p=0.042)$, confirming that increasing the length of the chain has a significant effect. Finally, model (4) indicates that the absence of transparency coupled with a longer chain reduces significantly the amount received compared to 1-Int-I. In contrast, transparency does not impact the amount received when the chain is short.

At least three reasons may explain that the amount received decreases in the number of intermediaries. First, senders may donate less when the number of potential embezzlers increases because it raises the implicit price of giving. Second, a longer chain may imply mechanically more embezzlement if each intermediary embezzles. Third, each intermediary may embezzle a higher share of the amount received in long chains because he can hide behind the other intermediary. In the next sections we explore these potential explanations.

\subsection{Impact of expected embezzlement on senders' donations}

Our second result summarizes our findings on senders' behavior:

Result 2 (Senders'donations) a) Senders donate less in the presence of intermediaries, and their donation decreases when the length of the chain increases. $b$ ) Unexpectedly, transparency tends to reduce donations.

Support for Result 2. Table 2 indicates that in accordance with prediction P1 senders make positive donations in all treatments. The senders' generosity decreases as the number of intermediaries increases. While donations represent on average $25.61 \%$ of the endowment in 0 Int, this percentage decreases to $22.83 \%$ in the short chain treatments and to $18.17 \%$ in the long chain treatments. The decrease is significant in the long chain treatments $(p<0.001)$, not in the short chain treatments $(p=0.123)$; the difference between the short and the long chain treatments does not reach a standard level of significance $(p=0.114)$. These findings suggest that senders 
anticipate some embezzlement and react as if the presence of intermediaries increases the implicit price of donations.

The effect of transparency is intriguing. Overall, it is significant neither in the short chain treatments (the mean percentage donated is $22.33 \%$ in 1 -Int-NI and $23.33 \%$ in 1 -Int-I; $p=0.437$ ), nor in the long chain treatments (these percentages are $21.11 \%$ in 2 -Int-NI and $15.22 \%$ in 2 -IntI; $p=0.207)$. However, a visual inspection of the data shows that transparency inflates the share of null and minimal donations: in short chains, the share of null donations increases from $16.67 \%$ to $33 \%$ (proportion test: $p=0.035$ ) and in long chains the share of TS1000 donations increases from $18.33 \%$ to $35 \%(p=0.039)$. This difference is observed in both experimental locations, which rejects the possibility that it is driven by session effects.

To better understand the determinants of donations, in Table 4 column (1) reports the marginal effects of a Tobit model in which the dependent variable is the amount donated. The independent variables include dummy variables for each treatment, with 0 -Int-NI as the reference category, a control for the location and demographic variables (gender, age, marital status, religion and religiosity). Then, we report the marginal effects from a two-stage Heckman model that allows us to decompose the donation decision into two parts: the decision to donate, estimated by a Probit model (column (2)), and the choice of the amount of the donation conditionally on donating, estimated with an OLS model (column (3)). In the selection equation, the regressors are the same as in model (1). We exclude the Dar-es-Salaam variable from the OLS model for identification and we include the Inverse of the Mill's Ratio calculated from the selection equation to identify a potential selection bias. Robust standard errors are clustered at the matched group level.

Model (1) confirms the significant negative impact of the presence of intermediaries on senders' generosity in most treatments (1-Int-NI, 2-Int-NI and 2-Int-I). Interestingly, the Heckman model reveals that the sender's binary decision to donate is affected negatively by the 
presence of one intermediary where there is transparency (1-Int-NI treatment). Conditional on the decision to donate, the amount of the donation is affected negatively by the presence of intermediaries with respect to the Baseline. But the effect is only significant for the 2-Int-I treatment. Altogether these findings confirm that the length of the chain tends to decrease the senders' generosity, in accordance with prediction P2. This is consistent with the idea that senders care about the implicit price of donations (as found by Chlaß et al., 2015).

Table 4. Determinants of the senders' decisions

\begin{tabular}{|c|c|c|c|}
\hline Dependent variables & $\begin{array}{c}\text { Amount donated } \\
\text { Tobit } \\
(1) \\
\end{array}$ & $\begin{array}{l}p(\text { donation }) \\
\text { Probit } \\
(2) \\
\end{array}$ & $\begin{array}{c}\text { Conditional } \\
\text { amount donated } \\
\text { OLS (3) }\end{array}$ \\
\hline O-Int-I treatment & Ref. & Ref. & Ref. \\
\hline 1-Int-I treatment & $\begin{array}{l}-520.815 \\
(382.06)\end{array}$ & $\begin{array}{c}-0.306 * * * \\
(0.092)\end{array}$ & $\begin{array}{l}-707.052 \\
(1157.16)\end{array}$ \\
\hline 1-Int-NI treatment & $\begin{array}{c}-484.778 * \\
(294.67)\end{array}$ & $\begin{array}{l}-0.121 \\
(0.080)\end{array}$ & $\begin{array}{c}-1009.127^{\#} \\
(610.259)\end{array}$ \\
\hline 2-Int-I treatment & $\begin{array}{c}-983.440 * * * \\
(245.36)\end{array}$ & $\begin{array}{l}-0.096 \\
(0.074)\end{array}$ & $\begin{array}{c}-2138.499 * * * \\
(504.935)\end{array}$ \\
\hline 2-Int-NI treatment & $\begin{array}{c}-540.882 * \\
(317.48)\end{array}$ & $\begin{array}{l}-0.120 \\
(0.278)\end{array}$ & $\begin{array}{c}-1033.673^{\#} \\
(671.671)\end{array}$ \\
\hline Dar-es-Salaam & $\begin{array}{l}-38.820 \\
(231.2)\end{array}$ & $\begin{array}{c}-0.083 * * \\
(0.038)\end{array}$ & - \\
\hline Male & $\begin{array}{l}193.187 \\
(245.88)\end{array}$ & $\begin{array}{l}-0.018 \\
(0.042)\end{array}$ & $\begin{array}{c}439.383 \\
(382.566)\end{array}$ \\
\hline Age & $\begin{array}{c}53.579 \\
(65.891)\end{array}$ & $\begin{array}{l}-0.010 \\
(0.007)\end{array}$ & $\begin{array}{c}71.411 \\
(109.227)\end{array}$ \\
\hline Married & $\begin{array}{l}285.187 \\
(509.12)\end{array}$ & $\begin{array}{c}0.004 \\
(0.082)\end{array}$ & $\begin{array}{c}854.236 \\
(504.448)\end{array}$ \\
\hline Christian & $\begin{array}{l}-429.253 \\
(337.23)\end{array}$ & $\begin{array}{l}-0.066 \\
(0.044)\end{array}$ & $\begin{array}{l}-806.115 \\
(510.885)\end{array}$ \\
\hline Religious practice & $\begin{array}{c}276.947 * * * \\
(107.39)\end{array}$ & $\begin{array}{c}0.042 * * \\
(0.018)\end{array}$ & $\begin{array}{c}587.255 \\
(246.004)\end{array}$ \\
\hline IMR & - & - & $\begin{array}{l}4486.815^{*} \\
(2480.012) \\
\end{array}$ \\
\hline $\begin{array}{l}\text { Nb of observations } \\
\text { Left/right censored obs. } \\
\text { Log pseudo-likelihood }\end{array}$ & $\begin{array}{c}356 \\
60 / 5 \\
-2864.32 \\
\end{array}$ & $\begin{array}{c}356 \\
- \\
-144.431\end{array}$ & 297 \\
\hline
\end{tabular}

Notes: All treatments are included. Table 4 reports marginal effects from Tobit estimates (1) and from a Heckman model ((2) and (3)). Robust standard errors are clustered at the matched group level. ***, **, and * indicate significance at the $0.01,0.05$, and 0.10 level, respectively. \# indicates significance at 0.11 level.

The fact that when there is transparency senders are less willing to donate anything in short chains and more willing to donate the smallest possible positive amount in long chains contradicts our prediction P3. ${ }^{25}$ A first possible explanation is that senders who care about the

\footnotetext{
${ }^{25}$ This is intriguing also because Dana et al. (2006) have shown that donors tend to be less generous in the regular
} 
amount received by the recipient lower their donation if they expect that transparency reduces embezzlement. However, this is inconsistent with the negative reaction of senders to a longer chain and with the fact that in short chains with transparency they become more likely to donate nothing. A second possibility is that transparency crowds-out the intrinsic motivation of the senders who derive a warm glow utility from giving a small amount as long as their donation is concealed. However, close inspection of the data shows that transparency reduces the share of large donations. ${ }^{26} \mathrm{~A}$ third possibility is that the transparency intervention increases the saliency of the risk of embezzlement, which may make senders more pessimistic about the future of their donation. This remains consistent with our hypothesis that for senders $f_{12}>0$.

Finally, Table 3 indicates that a more frequent religious practice increases donations while studying in Dar-es-Salaam impacts negatively the probability to donate, suggesting that prosocial norms are weaker in more individualized urban contexts than in the countryside.

\subsection{Embezzlement by intermediaries}

We first present aggregate results before investigating how intermediaries behave at the individual level.

Result 3. (Intermediaries' embezzlement, aggregate level) a) A longer transfer chain increases the percentage of the donation that is embezzled in total. b) Transparency has a weak negative effect on the aggregate level of embezzlement.

Support for Result 3. As indicated in Table 2 and Figure 2, the mean total percentage of the amount donated by the senders that is embezzled is higher both when the transfer chain is longer and when there is no transparency. Indeed, this percentage is $50.55 \%$ in 1-Int-I, $62.04 \%$ in 1-IntNI, 71.76\% in 2-Int-I and 74.88\% in 2-Int-NI. Wilcoxon Mann-Whitney tests indicate that the difference between 1-Int-I and 2-Int-I is highly significant $(p=0.005)$, while the difference

\footnotetext{
dictator game when there is uncertainty for the recipient on whether his earnings result on the sender's decision.

${ }^{26}$ Donations above TS8000 disappear in 1-Int-I while they represent $10 \%$ of the donations in 1-Int-NI; similarly, they represent $1.67 \%$ in 2-Int-I instead of $8.34 \%$ in 2-Int-NI.
} 
between 1-Int-NI and 2-Int-NI fails significance by a little $(p=0.115)$. Transparency reduces embezzlement, but not significantly so ( $p=0.121$ when comparing 1 -Int-NI and 1 -Int-I and $p=0.701$ when comparing 2-Int-NI and 2-Int-I).

However, these aggregate results may hide contrasted differences at the individual level. Next, we explore the individual determinants of embezzlement, summarized in Result 4.

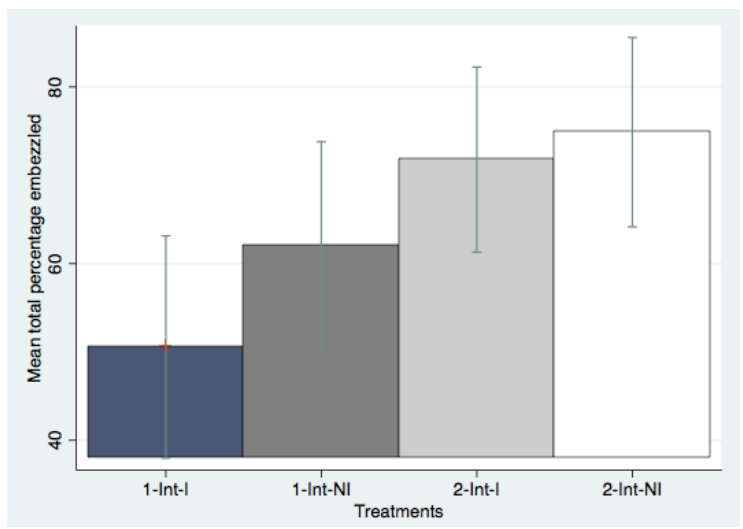

Figure 2. Mean total percentage of the amount donated by the sender that is embezzled by intermediaries, by treatment

Result 4 (Intermediaries' embezzlement, individual level) a) The percentage embezzled is smaller when the chain is longer because first intermediaries embezzle less than intermediaries in short chains. $b$ ) Transparency tends to reduce embezzlement except for the first intermediaries in long chains.

Support for Result 4. Table 2 indicates that when there is no transparency the mean percentage of the amount received from the previous player (either the sender or the first intermediary) that is embezzled by an intermediary is lower in a long chain (48.49\% in 2-Int-NI) than in a short chain $(62.04 \%$ in 1 -Int-NI; $p=0.085) .{ }^{27}$ This is driven by the specific behavior of the first intermediaries. Indeed, when there is no transparency the first intermediaries embezzle significantly less than single intermediaries in short chains $(39.79 \%$ vs. $62.04 ; p=0.014)$, while the second intermediaries embezzle more than the first ones $(60.69 \% ; p=0.053)$ and as much as

\footnotetext{
${ }^{27}$ Importantly, these percentages indicate that intermediaries transfer a much higher share of the amount received than senders. This confirms that intermediaries did not play as in a simple dictator game and that they understood that their role is to transfer money to the recipients.
} 
the single ones $(p=0.818)$. This finding holds for different levels of donations, as shown in Figure 3 that displays the embezzlement percentage for three categories of amount received $(1000,2000$ and 3000, 4000 and more). ${ }^{28}$ The first intermediaries' behavior contradicts the replacement logic according to which an individual becomes more likely to steal if he expects that if he does not do it himself, somebody else will do it anyway. Instead of relaxing the cost of deviating from the moral ideal of honesty because of the opportunity to share shame with the next intermediary, first intermediaries behave as if they were trying to compensate for the anticipated dishonesty of others. This result is consistent with our prediction P5 based on the assumption that for the first intermediaries the marginal social utility of the transfer decreases with the expected transfer of the second intermediary (i.e. $\left.f_{12}<0\right)$.

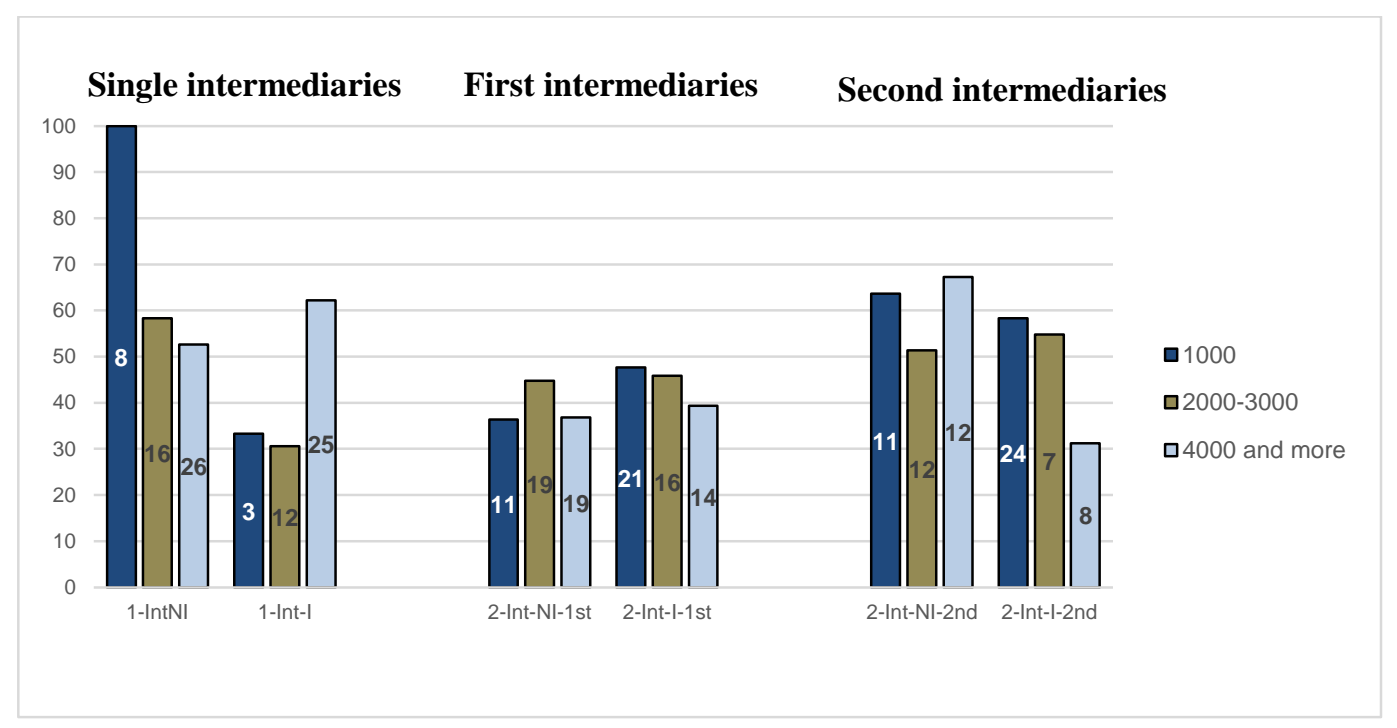

Figure 3. Mean percentage of the amount received embezzled, by category of amount received, treatment and rank

Note: The number on each bar corresponds to the number of observations. The percentages are conditional on receiving a positive amount to transfer.

Introducing transparency in short chains decreases the mean percentage embezzled from $62.04 \%$ in 1 -Int-NI to $50.55 \%$ in 1 -Int-I but the difference fails significance $(p=0.122)$. Figure 3 shows that this is mainly observed for donations below TS4000: observability generates a higher

\footnotetext{
${ }^{28}$ This division is arbitrary but guarantees a sufficient number of observations in each cell.
} 
moral cost when the initial donation was already small. We do not see the same pattern in long chains where the mean percentage embezzled is $47.97 \%$ in 2-Int-I, which differs neither from $48.49 \%$ in 2 -Int-NI $(p=0.995)$, nor from $50.55 \%$ in 1 -Int-I $(p=0.876)$. This hides, however, different dynamics for the first and the second intermediaries. Indeed, the second intermediaries tend to embezzle less $(52.14 \%$ instead of $60.69 \%$; $p=0.575)$, like single intermediaries in short chains $(p=0.662)$. In contrast, the first intermediaries embezzle slightly more $(44.78 \%$ instead of $39.79 \%, p=0.485)$. None of these effects are statistically significant, though. As a result, with transparency the difference of position in the chain is no longer significant $(p=0.412)$.

The previous analysis is based on means but some effects can be seen at corners. The share of intermediaries who transfer the integrality of the amount received is smaller in short chains $(26.67 \%)$ than in long chains $(38.51 \%)$ (proportion test: $p=0.055)$. On the opposite corner, the share of players who embezzle fully decreases significantly with transparency (from $37.31 \%$ without transparency to $28.46 \%$ with transparency; proportion test, $p=0.063$ ).

We next turn to a regression analysis. Table 5 reports estimates on the determinants of intermediaries' individual decisions broken into three panels. The first panel presents Probit models explaining full dishonesty: the dependent variable is equal to 1 if the intermediary embezzles the totality of the amount received, and 0 otherwise. The second panel explores the opposite corner and presents Probit models explaining full honesty: the dependent variable is equal to 1 if the intermediary transfers the totality of the amount received, and 0 otherwise. The last panel reports on Tobit models in which the dependent variable is the percentage embezzled. Each panel reports the marginal effects from three regressions, one pooling the data of all treatments, one restricted to the short chains and one restricted to the long chains. Robust standard errors are clustered at the matched group level.

The independent variables include the amount received, the experimental location and demographic controls. The regressions on pooled data add dummies for the size of the chain and 
for the absence of transparency. Those on long chains also include a dummy indicating whether the subject is the first intermediary and a variable interacting this dummy with the 2-Int-NI treatment to capture a potential rank-specific effect of the absence of transparency. 
Table 5. Determinants of the percentage of the amount received embezzled by each intermediary

\begin{tabular}{|c|c|c|c|c|c|c|c|c|c|}
\hline & \multicolumn{3}{|c|}{$\begin{array}{l}\text { Probability of being fully dishonest } \\
\text { (Probit) }\end{array}$} & \multicolumn{3}{|c|}{$\begin{array}{l}\text { Probability of being fully honest } \\
\text { (Probit) }\end{array}$} & \multicolumn{3}{|c|}{$\begin{array}{l}\text { Percentage of the amount received embezzled } \\
\text { (Tobit) }\end{array}$} \\
\hline & $\begin{array}{l}\text { All chains } \\
\text { (1) }\end{array}$ & $\begin{array}{c}\text { Short chains } \\
\text { (2) }\end{array}$ & $\begin{array}{c}\text { Long chains } \\
\text { (3) }\end{array}$ & $\begin{array}{c}\text { All chains } \\
\text { (4) }\end{array}$ & $\begin{array}{l}\text { Short chains } \\
\text { (5) }\end{array}$ & $\begin{array}{c}\text { Long chains } \\
\text { (6) }\end{array}$ & $\begin{array}{c}\text { All chains } \\
\text { (7) }\end{array}$ & $\begin{array}{c}\text { Short chains } \\
\text { (8) }\end{array}$ & $\begin{array}{c}\text { Long chains } \\
\text { (9) }\end{array}$ \\
\hline Long chain & $\begin{array}{l}-0.091 \\
(0.067)\end{array}$ & - & - & $\begin{array}{c}0.139 * * \\
(0.061)\end{array}$ & - & - & $\begin{array}{c}-0.025 * * \\
(0.011)\end{array}$ & - & - \\
\hline No transparency & $\begin{array}{c}0.129 * * \\
(0.060)\end{array}$ & - & - & $\begin{array}{l}-0.011 \\
(0.060)\end{array}$ & - & - & $\begin{array}{c}0.014 \\
(0.011)\end{array}$ & - & - \\
\hline 1-Int-I treatment & & Ref. & - & & Ref. & - & - & Ref. & - \\
\hline 1-Int-NI treatment & & $\begin{array}{c}0.247 * * \\
(0.109)\end{array}$ & - & & $\begin{array}{l}-0.057 \\
(0.097)\end{array}$ & - & - & $\begin{array}{l}0.049^{*} \\
(0.030)\end{array}$ & - \\
\hline 2-Int-I treatment & & - & Ref. & & - & Ref. & - & - & Ref. \\
\hline 2-Int-NI treatment & & - & $\begin{array}{l}0.167 \# \\
(0.102)\end{array}$ & & - & $\begin{array}{l}-0.199 * \\
(0.113)\end{array}$ & - & - & $\begin{array}{l}0.032 \# \\
(0.019)\end{array}$ \\
\hline Amount received & $\begin{array}{c}<-0.001 * * * \\
(<0.001)\end{array}$ & $\begin{array}{l}<-0.001 * \\
(<0.001)\end{array}$ & $\begin{array}{c}<-0.001 * * * \\
\quad(<0.001)\end{array}$ & $\begin{array}{l}<0.001 \\
(<0.001)\end{array}$ & $\begin{array}{l}<0.001 \\
(<0.001)\end{array}$ & $\begin{array}{l}<-0.001 \\
(<0.001)\end{array}$ & $\begin{array}{c}<-0.001 * * \\
(<0.001)\end{array}$ & $\begin{array}{l}<-0.001 \\
(<0.001)\end{array}$ & $\begin{array}{c}<-0.001 * * * \\
(<0.001)\end{array}$ \\
\hline $\begin{array}{l}1^{\text {st }} \text { intermediary } \\
1^{\text {st }} \text { intermediary } \\
* 2 \text {-Int-NI treatment }\end{array}$ & - & - & $\begin{array}{c}-0.135 \\
(0.108) \\
0.001 \\
(0.142)\end{array}$ & & - & $\begin{array}{c}-0.070 \\
(0.122) \\
0.320 * * \\
(0.155)\end{array}$ & $\begin{array}{c}- \\
- \\
-\end{array}$ & $\begin{array}{c}(20.001) \\
-\end{array}$ & $\begin{array}{l}-0.006 \\
(0.018) \\
-0.029 \\
(0.025)\end{array}$ \\
\hline Dar-es-Salaam & $\begin{array}{c}0.266 * * * \\
(0.055)\end{array}$ & $\begin{array}{c}0.480 * * * \\
(0.099)\end{array}$ & $\begin{array}{c}0.190 * * * \\
(0.070)\end{array}$ & $\begin{array}{c}-0.223 * * * \\
(0.057)\end{array}$ & $\begin{array}{c}-0.187 * * \\
(0.086)\end{array}$ & $\begin{array}{c}-0.286^{* * * *} \\
(0.071)\end{array}$ & $\begin{array}{c}0.049 * * * \\
(0.012)\end{array}$ & $\begin{array}{c}0.112 * * * \\
(0.037)\end{array}$ & $\begin{array}{c}0.041 * * * \\
(0.014)\end{array}$ \\
\hline Male & $\begin{array}{l}0.136 * * \\
(0.063)\end{array}$ & $\begin{array}{c}0.071 \\
(0.135)\end{array}$ & $\begin{array}{c}0.213 * * * \\
(0.076)\end{array}$ & $\begin{array}{c}-0.209 * * * \\
(0.072)\end{array}$ & $\begin{array}{l}-0.231 * \\
(0.128)\end{array}$ & $\begin{array}{l}-0.262 * * * \\
(0.091)\end{array}$ & $\begin{array}{l}0.036^{* * *} \\
(0.013)\end{array}$ & $\begin{array}{c}0.041 \\
(0.033)\end{array}$ & $\begin{array}{c}0.045^{* * *} * \\
(0.015)\end{array}$ \\
\hline Age & -0.008 & -0.006 & -0.018 & $0.027 * *$ & $0.052 * * *$ & 0.017 & $-0.003^{*}$ & -0.007 & -0.004 \\
\hline Married & $\begin{array}{c}(0.010) \\
0.136\end{array}$ & $\begin{array}{l}(0.018) \\
0.428^{\#} \\
(0261)\end{array}$ & $\begin{array}{l}(0.014) \\
-0.068\end{array}$ & $\begin{array}{l}(0.011) \\
-0.131\end{array}$ & $\begin{array}{c}(0.019) \\
-0.281 * * *\end{array}$ & $(0.016)$ & $\begin{array}{l}(0.002) \\
0.023\end{array}$ & $\begin{array}{l}(0.004) \\
0.139 * * *\end{array}$ & $\begin{array}{l}(0.002) \\
-0.035\end{array}$ \\
\hline Christian & $\begin{array}{l}(0.195) \\
-0.128^{\#}\end{array}$ & $\begin{array}{c}(0.261) \\
-0.390 * * *\end{array}$ & $\begin{array}{c}(0.182) \\
0.015\end{array}$ & $\begin{array}{c}(0.120) \\
0.096\end{array}$ & $\begin{array}{c}(0.057) \\
-0.048\end{array}$ & $\begin{array}{l}(0.201) \\
0.172 *\end{array}$ & $\begin{array}{l}(0.025) \\
-0.023\end{array}$ & $\begin{array}{c}(0.037) \\
-0.047\end{array}$ & $\begin{array}{l}(0.353) \\
-0.013\end{array}$ \\
\hline Religious practice & $\begin{array}{c}(0.079) \\
-0.025 \\
(0.027)\end{array}$ & $\begin{array}{l}(0.144) \\
-0.081 * \\
(0.046) \\
\end{array}$ & $\begin{array}{c}(0.091) \\
0.010 \\
(0.035) \\
\end{array}$ & $\begin{array}{c}(0.076) \\
0.044 \\
(0.030) \\
\end{array}$ & $\begin{array}{c}(0.037) \\
0.123 * * * \\
(0.044) \\
\end{array}$ & $\begin{array}{c}(0.090) \\
0.005 \\
(0.042) \\
\end{array}$ & $\begin{array}{l}(0.014) \\
-0.008 * \\
(0.005) \\
\end{array}$ & $\begin{array}{c}(0.037) \\
-0.036^{* * *} \\
(0.014) \\
\end{array}$ & $\begin{array}{l}(0.015) \\
-0.001 \\
(0.006) \\
\end{array}$ \\
\hline $\begin{array}{l}\text { Number of obs. } \\
\text { Log pseudo-likelih. } \\
\text { Left/right cens. obs. }\end{array}$ & $\begin{array}{c}261 \\
-143.867 \\
-\end{array}$ & $\begin{array}{c}90 \\
-39.96 \\
- \\
\end{array}$ & $\begin{array}{c}171 \\
-92.161 \\
-\end{array}$ & $\begin{array}{c}261 \\
-150.418 \\
-\end{array}$ & $\begin{array}{c}90 \\
-42.160 \\
-\end{array}$ & $\begin{array}{c}171 \\
-99.028 \\
-\end{array}$ & $\begin{array}{c}261 \\
-264.227 \\
90 / 87\end{array}$ & $\begin{array}{c}90 \\
-79.794 \\
24 / 31\end{array}$ & $\begin{array}{c}171 \\
-171.994 \\
66 / 56\end{array}$ \\
\hline
\end{tabular}

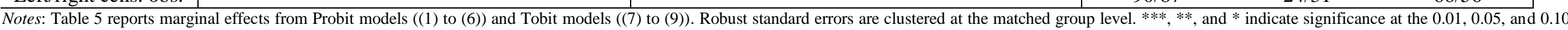
level, respectively. \# indicates significance at the 0.11 level. 
First, Table 5 confirms that the probability of being fully honest is 13.9 points higher (model (4)) in long chains than in short chains and that the percentage embezzled by an intermediary is significantly smaller (model (7)). Thus, if at the aggregate level a longer transfer chain increases the total percentage embezzled (Result 3), this result is driven mainly by a mechanical effect.

Second, the probability of being fully dishonest increases by 12.9 points when there is no transparency (model (1)). This effect is stronger in short chains (model (2)) than in long chains (model (3)). In short chains without transparency, the probability of being fully dishonest increases by $24.7 \%$ (model (2)) and the percentage embezzled by $4.9 \%$ (model (8)): embezzlement reacts to variations in its moral cost. We do not find such a global effect in long chains (see models (3) and (9)). However, while the first intermediary is $32 \%$ more likely to be fully honest than the second intermediary in the absence of information (which confirms P5), transparency eliminates the difference between the two intermediaries (model (6)). Indeed, transparency increases by $19.9 \%$ the second intermediary's probability of being fully honest while it reduces this probability for the first intermediary by $12.1 \%$. The disciplining effect of transparency works also in long chains, but at the upper margin; in contrast to short chains, it is null on the lower margin (see model (3)). Our model helps interpreting these findings. The direct effect of transparency increases the moral cost of behaving dishonestly because of (individual or shared) shame, and this motivates intermediaries to reduce embezzlement regardless of the length of the chain and on the position in the chain. However, transparency has an ambiguous impact on the first intermediaries, as stated in prediction P6. Indeed, its direct effect can be traded-off by its indirect effect through higher expectations about the honesty of the second intermediaries induced by transparency. Expecting less embezzlement from the second intermediary because of transparency reduces the disutility of deviating from their moral ideal and lead them to behave less honestly. This can explain that they are no more honest than the second intermediaries under transparency. 
Third, Table 5 reveals that when the amount received is larger, intermediaries are less likely to be fully dishonest and they embezzle a lower percentage of the donation. There are two interpretations. Previous literature has shown that people do not lie in full because they want to keep a positive self-concept (Mazar et al., 2008; Shalvi et al., 2011; Fischbacher and FöllmiHeusi, 2013). When observing that previous players in the chain have been more generous, full dishonesty probably makes it more difficult for people to keep a good image of themselves. ${ }^{29} \mathrm{~A}$ second interpretation is the existence of an income target: if the donation is more generous, they take a lower percentage of it. Our design does not allow us to disentangle between these two interpretations. Finally, Table 5 confirms the existence of weaker norms in Dar-es-Salaam: subjects there are more likely to be fully dishonest, less likely to be fully honest and they embezzle a higher percentage of the donation. The same applies to males in long chains whereas a more frequent religious practice reduces embezzlement in short chains.

\section{Discussion and conclusion}

Embezzlement is a major issue. We have developed an original model and conducted an experiment to investigate whether the organization of the transfer chain and transparency on donations can discourage embezzlement and motivate higher donations. Our experiment corroborates most of our theoretical predictions. A key finding is that the recipients' final earnings are lower in the presence of intermediaries, especially when intermediaries are more numerous and recipients are not informed about the amount donated by the senders.

A first explanation lies in the fact that senders are less generous when their transfer cannot be made directly, revealing the expectation of embezzlement especially in long chains. More surprisingly, senders react negatively to transparency. An interpretation is that transparency makes the possibility of embezzlement more salient to them, which reduces the moral cost of

\footnotetext{
${ }^{29}$ This result is unlikely driven by the intermediaries' willingness to equalize their payoff with that of the recipients. Indeed, conditional on receiving at last TS3000, only $11.76 \%$ of the intermediaries transfer 3000 (which would equalize the recipient's payoff and the initial endowment of the intermediary). More generally, there are only 13 observations out of 360 in which the final payoff of the recipient is equal to that of the intermediary.
} 
deviating from their moral ideal of generosity. A second explanation lies in the mechanical effect of the length of the transfer chain. The higher total percentage embezzled in long chains is due to the fact that more intermediaries are in a position to take money. This is not driven by a higher percentage taken by each link in the chain permitted by the fact that each one can hide behind the other. Indeed, when there is no transparency, the first intermediaries embezzle less than the second ones. They are more likely to refrain from taking money when they expect more embezzlement in the chain. This care for the recipients' welfare contradicts the replacement logic and the idea that more links reduce the sense of responsibility. Our model with referencedependent preferences in terms of moral ideal explains that the direct effect of transparency increases the moral cost of embezzlement because of shame, whereas its indirect effect plays in the opposite direction for the first intermediaries who anticipate that transparency will reduce embezzlement by the following intermediary.

The fact that individuals, belonging to the same subject-pool and assigned randomly to a role, show different preferences depending on their position in the transfer chain is quite remarkable. Senders express concerns for the implicit price of their donation while intermediaries express concerns for the situation of their potential victim. Expecting dishonesty from the next players reduces the loss aversion from deviating from one's moral ideal for the senders but increases it for the intermediaries at the beginning of the chain. An interpretation is that the reference point differs between senders and intermediaries: senders decide in the loss domain (accepting a reduction of earnings to get closer to the moral ideal) while intermediaries decide in the gain domain (accepting not to increase earnings to get closer to the moral ideal). Heterogeneity is also transversal to the roles. While some intermediaries resist the temptation and that others embezzle everything, embezzlement is most of the time incomplete even in the 
absence of sanctions. ${ }^{30}$ This extends the previous literature on heterogeneity of attitudes towards dishonesty (Gibson et al., 2013) by showing that the latter also depend on the expectations about others' moral firmness, since the position in the chain makes a difference.

In terms of policy, our results suggest that shortening the transfer chain would improve the welfare of recipients. The advantages of transparency depend on how the chain is organized. Incidentally, we suggest that in long chains interventions should target the final link instead of the first ones. It is also important to pay attention to how information is communicated to avoid that transparency makes dishonesty more salient and reduce the willingness to donate.

Of course, we need to be careful regarding the extrapolation of our findings. We acknowledge some limitations that suggest a number of extensions. It would be interesting to study how repeated interactions affect embezzlement and to explore higher degrees of transparency. Allowing intermediaries to observe the (dis)honesty of the previous individuals in the chain would enable us to study whether or not peer effects, if any, are symmetric. While our experiment is based on a zero-sum game, it might be interesting to introduce negative externalities of embezzlement. Other manipulations include variations in the organization of the transfer chain (for example, introducing elected intermediaries or varying the intermediaries' relative income). It might be also interesting to replicate this study in other countries to better appreciate the role of these norms. This is left for further investigation.

\footnotetext{
${ }^{30}$ This is consistent with the theory of maintenance of self-concept (Mazar et al., 2008; Fischbacher and FöllmiHeusi, 2013; Shalvi et al., 2011) which explains that most people are willing to cheat to earn more but they do not exploit their cheating opportunities in full in order to keep a good image of themselves.
} 


\section{Reference list}

Abbink, K., Irlenbusch, B., Renner, E. (2002). An Experimental Bribery Game. Journal of Law, Economics, and Organization 18(2), 428-454.

Abbink, K., Ellmann, M. (2010). The donor problem: an experimental analysis of beneficiary empowerment. Journal of Development Studies 46(8), 1327-1344.

Abbink, K., Serra, D. (2012). Anti-corruption policies: Lessons from the lab.In D. Serra \& L. Wantchekon (Eds.), New advances in experimental research on corruption (Vol. 15). Bingley: Emerald Group Publishing

Abeler, J., Becker, A., Falk, A. (2014). Representative evidence on lying costs. Journal of Public Economics 113, 96-104.

Armantier, O. and A. Boly (2011). A controlled field experiment on corruption. European Economic Review 55, 1072-1082.

Armantier, O. and A. Boly (2012). On The External Validity of Corruption Experiments. In D. Serra and L. Wantchekon (Eds.) New Advances in Experimental Research on Corruption, Research in Experimental Economics, Volume 15. Emerald Group Publishing.

Azfar, O., Nelson, W.R. (2007). Transparency, Wages, and the Separation of Powers: An Experimental Analysis of Corruption. Public Choice 130(3-4), 471-493.

Bahr, G., Requate, T. Reciprocity and Giving in a Consecutive Three-Person Dictator Game with Social Interaction. German Economic Review 15(3), 374-392.

Banerjee, A., Hanna, R., Mullainathan, S. (2012). Corruption. In R. Gibbons and J. Roberts (Eds.), Handbook of organizational economics, Princeton: Princeton University Press.

Banerjee, R., Baul, T., Rosenblat, T. (2015). On self selection of the corrupt into the public sector. Economics Letters 127, 43-46.

Banuri, S., Eckel, C. (2015). Cracking down on bribery. Social Choice and Welfare 45, 579-600.

Bardhan, P. (1997). Corruption and development: A review of issues. Journal of Economic Literature 35, 1320-1346.

Barr, A., Lindelöw, M., Serneels, P. (2009). Corruption in public service delivery: An experimental analysis. Journal of Economic Behavior \& Organization 72, 225-239.

Barr, A., Serra, D. (2010). Corruption and culture: An experimental analysis. Journal of Public Economics 194, 862-869.

Beekman, G., Bulte, E., Nillesen, E. (2014). Corruption, investments and contributions to public goods: Experimental evidence from rural Liberia. Journal of Public Economics 15, 37-47.

Bertrand, M., Djankov, S., Hanna, R., Mullainthan, S. (2007). Obtaining a Driving License in India: An Experimental Approach to Studying Corruption. The Quarterly Journal of Economics November 122(4), 1639-1676.

Bucciol, A., Piovesan, M. (2011). Luck or cheating? A field experiment on honesty with children. Journal of Economic Psychology 32 (1), 73-78.

Cameron, L., Chaudhuri, A., Erkal, N., Gangadharan, L. (2009). Propensities to engage in and punish corrupt behavior: Experimental evidence from Australia, India, Indonesia and Singapore. Journal of Public Economics 93(7-8), 843-851.

Chlaß, N., Gangadharan, L., Jones, K. (2015). Charitable Giving and Intermediation. Discussion Paper 18/15. Monash Business School. 
Dana, J., Cain, D.M., Dawes, D.R. (2006). What You Don't Know Won't Hurt Me. Costly (But Quiet) Exit in Dictator Games. Organizational Behavior and Human Decision Processes 100, 193-201.

Dana, J., Weber, R., Kuang J.X. (2007). Exploiting Moral Wriggle Room: Experiments demonstrating an illusory preference for fairness. Economic Theory 33, 67-80.

Dohmen, T., Falk, A., Huffman, D., Sunde, U., Schupp, J., Wagner, G.G. (2011). Individual Risk Attitudes: Measurement, Determinants, And Behavioral Consequences. Journal of the European Economic Association 9(3), 522-550.

Drugov, M., Hamman, J., Serra, D. (2014). Intermediaries in Corruption: An Experiment. Experimental Economics 17(1), 78-99.

Fan, C.S., Lin, C. Treisman, D. (2010). Embezzlement Versus Bribery, National Bureau of Economic Research Working Paper 16542, http://www.nber.org/papers/w16542.

Fantaye, D.K. (2004). Fighting Corruption and Embezzlement in Third World Countries. Journal of Criminal Law 68(2), 170-176.

Fischbacher, U., Föllmi-Heusi, F. (2013). Lies in disguise: An experimental study on cheating. Journal of the European Economic Association 11, 525-547.

Fisman, R., Schulz, F., and V. Vig (2014). The Private Returns to Public Office. Journal of Political Economy 122(4), 806-862.

Forsythe, R., Horowitz, J., Savin, N. E., Sefton, M. (1994). Fairness in simple bargaining experiments. Games and Economic Behavior 6, 347-369.

Gibson, R., Tanner, C., Wagner, A. F. (2013). Preferences for truthfulness: Heterogeneity among and within individuals. American Economic Review 103, 532-548.

Gneezy, U. (2005). Deception: The role of consequences. American Economic Review, 95, 384 394.

Gneezy, U., Saccardo, S., van Veldhuizen (2015). Bribery: Greed versus Reciprocity. Mimeo.

Gray, H.S. (2015). The political economy of grand corruption in Tanzania. African Affairs 114/456, 382-403.

Green, G. (1993). White-collar crime and the study of embezzlement. Annals of the American Academy of Political and Social Science 525, 95-106.

Güth, W., Huck, S., Ockenfels, P. (1996). Two-level ultimatum bargaining with incomplete information. The Economic Journal 106(436), 593-604.

Hasker, K., Okten, C. (2008). Intermediaries and Corruption. Journal of Economic Behavior \& Organization 67, 103-115.

Hoffman, E., McCabe, K., Shachat, K. and Smith, V. (1994). Preferences, property rights and anonymity in bargaining games. Games and Economic Behavior 7, 346-380.

Huck, S. (1999). Responder behavior in ultimatum offer games with incomplete information. Journal of Economic Psychology 20, 183-206.

Irlenbusch, B., Villeval, M.C. (2015). Behavioral ethics: how psychology influenced economics and how economics might inform psychology? Current Opinion in Psychology 6, 87-92.

Kahneman, D., and Tversky, A. (1979). Prospect theory: An analysis of decisions under risk. Econometrica 47(2), 263-291. 
Kolstad, I., Wiig, A. (2009). Is Transparency the Key to Reducing Corruption in Resource-Rich Countries? World Development 37(3), 521-532.

Köszegi, B., and Rabin, M. (2006). A model of reference-dependent preferences. Quarterly Journal of Economics 121(4), 1133-1166.

Makowsky, M. D., and Wang, S. (2015). Embezzlement, Whistleblowing, and Organizational Structure. Mimeo.

Mazar, N., Amir, O., Ariely, D. (2008). The dishonesty of honest people: A theory of self-concept maintenance. Journal of Marketing Research 45, 633-644.

Olken, B.A. (2006). Corruption and the costs of redistribution: Micro evidence from Indonesia. Journal of Public Economics 90, 853-870.

Olken, B.A. (2007). Monitoring Corruption: Evidence from a Field Experiment in Indonesia. Journal of Political Economy 115(2), 200- 249.

Olken, B.A., Pande, R. (2011). Corruption in developing countries. NBER Working Paper 17398. http://www.nber.org/papers/w17398

Platteau, J.-P. (2004). Monitoring elite capture in community-driven development. Development and Change 35(2), 225-248.

Rapoport, A., Sundali, J.A. (1996). Ultimatums in two-person bargaining with one-sided uncertainty: Offer games. International Journal of Game Theory 25(4), 475-494.

Reinikka, R., Svensson, J. (2004). Local capture: evidence from a central government transfer program in Uganda. The Quarterly Journal of Economics 119, 679-705.

Reinikka, R., Svensson, J. (2011). The power of information in public services: Evidence from education in Uganda. Journal of Public Economics 95, 956-966

Rose-Ackerman, S. (1975). The Economics of Corruption. Journal of Public Economics 4, 1-17.

Sequeira, S. (2016). Corruption, Trade Costs and Gains from Tariff Liberalization: Evidence from Southern Africa. Mimeo.

Serra, D., Wantchekon, L. (Eds.) (2012). New Advances in Experimental Research on Corruption, Research in Experimental Economics, Volume 15. Emerald Group Publishing.

Shalvi, S., Dana, J., Handgraaf, M.J.J., De Dreu, C.K.W. (2011). Justified ethicality: observing desired counterfactuals modifies ethical perceptions and behavior. Organizational Behavior and Human Decision Processes 115, 181-190.

Shleifer, R., Vishny R.W. (1993). Corruption. The Quarterly Journal of Economics 108(3), 599617.

Transparency International (2014). Corruption perceptions index 2014. www.transparency.org.

Vicente, P. (2010). Does Oil Corrupt? Evidence from a Natural Experiment in West Africa, Journal of Development Economics 92(1), 28-38.

Vischer, T., Dohmen, T., Falk, A., Huffman, D., Schupp, J., Sunde, U., Wagner, G.G. (2013). Validating an Ultra-Short Survey Measure of Patience. Economics Letters 120(2), 142-145.

Winschel, E., Zahn, P. (2014). When Ignorance is Bliss. Information Asymmetries Enhance Prosocial Behavior in Dictator Games. University of Mannheim, Working Paper 13-07.

\section{Appendix 1. Instructions}




\section{Instructions for the 1-Int-NI treatment \\ (The differences with the 1-Int-I treatment are indicated in italics)}

We thank you for your participation in this experiment on decision-making. During this experiment, you will be able to earn Tanzanian Shillings (TS) in cash. Your decisions or responses to questions will be strictly anonymous and confidential. You will be identified only by an id code throughout the experiment.

In this experiment we randomly form groups of three people. Each group consists of one person A, one person B and one person $\mathrm{C}$. The identity of the other group members will remain anonymous throughout the experiment.

After reading the instructions, each of you will be randomly assigned to one of three different rooms that correspond to the three different roles. Once in the room, all the participants in this room will be assigned the same role. This means that all the participants A will be in the same room; all the participants B will be in another room and all the participants $\mathrm{C}$ will be in a third room. Once in your room, you will learn your role and you will never meet again the participants in the other roles.

\section{The task}

At the beginning of the experiment in each group, person A receives 15000 TS. Person B receives 5000 TS. Person $\mathrm{C}$ receives $2000 \mathrm{TS}$.

Person A has to decide how many TS to transfer to person C. Person A can choose any amount between 0 and 15 $000 \mathrm{TS}$, as multiples of $1000 \mathrm{TS}$ (either $0,1000,2000, \ldots, 15000$ ).

If person A sends money to person $\mathrm{C}$, the transfer has to be done through an intermediary, person $\mathrm{B}$. The role of person $\mathrm{B}$ is to transfer the money to person C. Person B is not allowed to transfer his own TS to person C.

Person $\mathrm{C}$ has no decision to make.

\section{If you are a person $A$}

You will receive a bag marked with the id number of your group of three. This bag contains two envelopes, white and brown.

- $\quad$ The white envelope contains $15000 \mathrm{TS}$.

- The brown envelope is empty and you can use it to transfer money to person C.

You have to decide how many TS you transfer to person $C$ through person B. You can transfer $0,1000,2000, \ldots$ up to $15000 \mathrm{TS}$.

Please use the bag to count your notes in the white envelope and to place discreetly the TS you want to transfer in the brown envelope.

The amount of TS that you leave in the white envelope is for you to take home. Keep the white envelope for yourself. Leave the brown envelope in the bag.

An assistant will collect the bags containing the brown envelope and give them to another assistant who will bring the bags to the room of persons B. There, the person B you are matched with will receive your bag marked with the id number of your group and containing the brown envelope.

Then you will receive instructions for the next task to complete before being allowed to leave the room.

\section{If you are a person $B$}

You will receive from the person A you are matched with a bag marked with the id number of your group of three. This bag contains two envelopes, white and brown.

- The white envelope contains 5000 TS for you to take home.

- The brown envelope contains the TS that the person A you are matched with wants you to transfer to the person $\mathrm{C}$ in your group.

Please use the bag to count discreetly the notes in the white envelope and in the brown envelope. 
After counting, you have to decide how many TS to leave in the brown envelope. You are not allowed to add any of your TS in the brown envelope. Keep the white envelope for yourself. Leave the brown envelope in the bag.

An assistant will collect the bags containing the brown envelope and give them to another assistant who will bring the bags to the room of persons $\mathrm{C}$. There, the person $\mathrm{C}$ you are matched with will receive the bag marked with the id number of your group and containing the brown envelope.

Then you will receive instructions for the next task to complete before being allowed to leave the room.

\section{If you are a person $\mathrm{C}$}

You will receive instructions for a task to complete.

Then, you will receive a bag marked with the id number of your group of three. This bag contains two envelopes, white and brown.

- $\quad$ The white envelope contains 2000 TS.

- The brown envelope contains the TS that the person B you are matched with transferred to you on behalf of person A. Person B cannot transfer any of his own TS to you.

The amount of TS in the white and the brown envelopes is for you to take home. Keep these envelopes for yourself. Leave the bag.

Then you will be allowed to leave the room.

\section{Information}

Person A does not know how many TS the person B has left in the brown envelope that was received by person C.

Person C does not know how many TS the person A has put in the brown envelope that was received by person B.

[This paragraph has been replaced with the following in the 1-Int-I treatment:

Person A does not know how many TS the person B has left in the brown envelope that was received by person C.

Person C knows how many TS the person A has put in the brown envelope that was received by person B.]

If you have any question, please raise your hand and an experimenter will come to you and answer your questions in private.

From now until the end of the experiment, it is strictly forbidden to talk, otherwise you will be excluded from the session and earnings.

\section{Instructions for the 2-Int-NI treatment \\ (The differences with the 2-Int-I treatment are indicated in italics)}

We thank you for your participation in this experiment on decision-making. During this experiment, you will be able to earn Tanzanian Shillings (TS) in cash. Your decisions or responses to questions will be strictly anonymous and confidential. You will be identified only by an id code throughout the experiment.

In this experiment we randomly form groups of four people. Each group consists of one person A, one person B1, one person B2, and one person C. The identity of the other group members will remain anonymous throughout the experiment.

After reading the instructions, each of you will be randomly assigned to one of four different rooms that correspond to the four different roles. Once in the room, all the participants in this room will be assigned the same role. This means that all the participants A will be in the same room; all the participants B1 will be in another room; all the participants $\mathrm{B} 2$ will be in a third room and all the participants $\mathrm{C}$ will be in a fourth room. Once in your room, you will learn your role and you will never meet again the participants in the other roles.

\section{The task}


At the beginning of the experiment in each group, person A receives 15000 TS. Person B1 and person B2 each receive 5000 TS. Person $C$ receives 2000 TS.

Person A has to decide how many TS to transfer to person C. Person A can choose any amount between 0 and 15 $000 \mathrm{TS}$, as multiples of $1000 \mathrm{TS}$ (either $0,1000,2000, \ldots, 15000$ ).

If person $\mathrm{A}$ sends money to person $\mathrm{C}$, the transfer has to be done through two successive intermediaries, person $\mathrm{B} 1$ and person B2. The role of persons B1 and B2 is to transfer the money to person C. Persons B are not allowed to transfer their own TS to person C.

Person $\mathrm{C}$ has no decision to make.

\section{If you are a person $\mathrm{A}$}

You will receive a bag marked with the id number of your group of four. This bag contains two envelopes, white and brown.

- $\quad$ The white envelope contains $15000 \mathrm{TS}$.

- The brown envelope is empty and you can use it to transfer money to person C.

You have to decide how many TS you transfer to person $\mathrm{C}$ through person $\mathrm{B}$. You can transfer $0,1000,2000, \ldots$ up to $15000 \mathrm{TS}$.

Please use the bag to count your notes in the white envelope and to place discreetly the TS you want to transfer in the brown envelope.

The amount of TS that you leave in the white envelope is for you to take home. Keep the white envelope for yourself. Leave the brown envelope in the bag.

An assistant will collect the bags containing the brown envelope and give them to another assistant who will bring the bags to the room of persons B1. There, the person B1 you are matched with will receive your bag marked with the id number of your group and containing the brown envelope.

Then you will receive instructions for the next task to complete before being allowed to leave the room.

\section{If you are a person $B 1$}

You will receive from the person A you are matched with a bag marked with the id number of your group of four. a bag marked with the id number of your group of three. This bag contains two envelopes, white and brown.

- The white envelope contains 5000 TS for you to take home.

- The brown envelope contains the TS that the person A you are matched with wants you to transfer to the person $\mathrm{C}$ in your group through person $\mathrm{B} 2$.

Please use the bag to count discreetly the notes in the white envelope and in the brown envelope.

After counting, you have to decide how many TS to leave in the brown envelope. You are not allowed to add any of your TS in the brown envelope. Keep the white envelope for yourself. Leave the brown envelope in the bag.

An assistant will collect the bags containing the brown envelope and give them to another assistant who will bring the bags to the room of persons B2. There, the person B2 you are matched with will receive the bag marked with the id number of your group and containing the brown envelope.

Then you will receive instructions for the next task to complete before being allowed to leave the room.

\section{If you are a person $\mathrm{B} 2$}

You will receive from the person A and the person B1 you are matched with a bag marked with the id number of your group of four. This bag contains two envelopes, white and brown.

- The white envelope contains 5000 TS for you to take home. 
- The brown envelope contains the TS that the person A you are matched with wants you to transfer to the person $\mathrm{C}$ in your group and that person $\mathrm{B} 1$ has left.

Please use the bag to count discreetly the notes in the white envelope and in the brown envelope.

After counting, you have to decide how many TS to leave in the brown envelope. You are not allowed to add any of your TS in the brown envelope. Keep the white envelope for yourself. Leave the brown envelope in the bag.

An assistant will collect the bags containing the brown envelope and give them to another assistant who will bring the bags to the room of persons $\mathrm{C}$. There, the person $\mathrm{C}$ you are matched with will receive the bag marked with the id number of your group and containing the brown envelope.

Then you will receive instructions for the next task to complete before being allowed to leave the room.

\section{If you are a person $\mathrm{C}$}

You will receive instructions for a task to complete.

Then, you will receive a bag marked with the id number of your group of four. This bag contains two envelopes, white and brown.

- The white envelope contains 2000 TS.

- The brown envelope contains the TS that the person B1 and the person B2 you are matched with transferred to you on behalf of person A. Persons B1 and B2 cannot transfer any of their own TS to you.

The amount of TS in the white and the brown envelopes is for you to take home. Keep these envelopes for yourself. Leave the bag.

Then you will be allowed to leave the room.

\section{Information}

Person A does not know how many TS the person B1 and then the person B2 have left in the brown envelope that was received by person $\mathrm{C}$.

Person B2 does not know how many TS the person B1 received from person A.

Person C does not know how many TS the person A has put in the brown envelope that was received by person B1 and then by person $\mathrm{B} 2$.

[This paragraph has been replaced with the following in the 2-Int-I treatment:

Person A does not know how many TS the person B1 and then the person B2 have left in the brown envelope that was received by person $C$.

Person $\mathbf{B} 2$ does not know how many TS the person B1 received from person A.

Person $C$ knows how many TS the person A has put in the brown envelope that was received by person $B 1$ and then by person B2.]

If you have any question, please raise your hand and an experimenter will come to you and answer your questions in private. From now until the end of the experiment, it is strictly forbidden to talk, otherwise you will be excluded from the session and earnings.

\section{Final instructions common to all treatments}

(These instructions were distributed in rooms A and B after the bags have been collected. They were distributed in room C before the bags were distributed) 
Please fill out the questionnaire that has been distributed to you. We remind you that all your responses are anonymous. Do not forget to mention your experimental id number at the top of this questionnaire. You receive 2 000 TS for answering this questionnaire.

Finally, you have an opportunity to earn extra money by tossing the coin that has been put on your table.

You can toss the coin as many times as you like, but you have to report only the first toss. Please toss the coin as discreetly as possible.

- If the first toss of the coin shows Head, you earn 2000 TS that will be added to your other payoffs.

- If the first toss of the coin shows Tail, you earn nothing in this task.

Please report at the end of the questionnaire form the outcome of your first coin toss. 
Appendix 2. The experimental settings

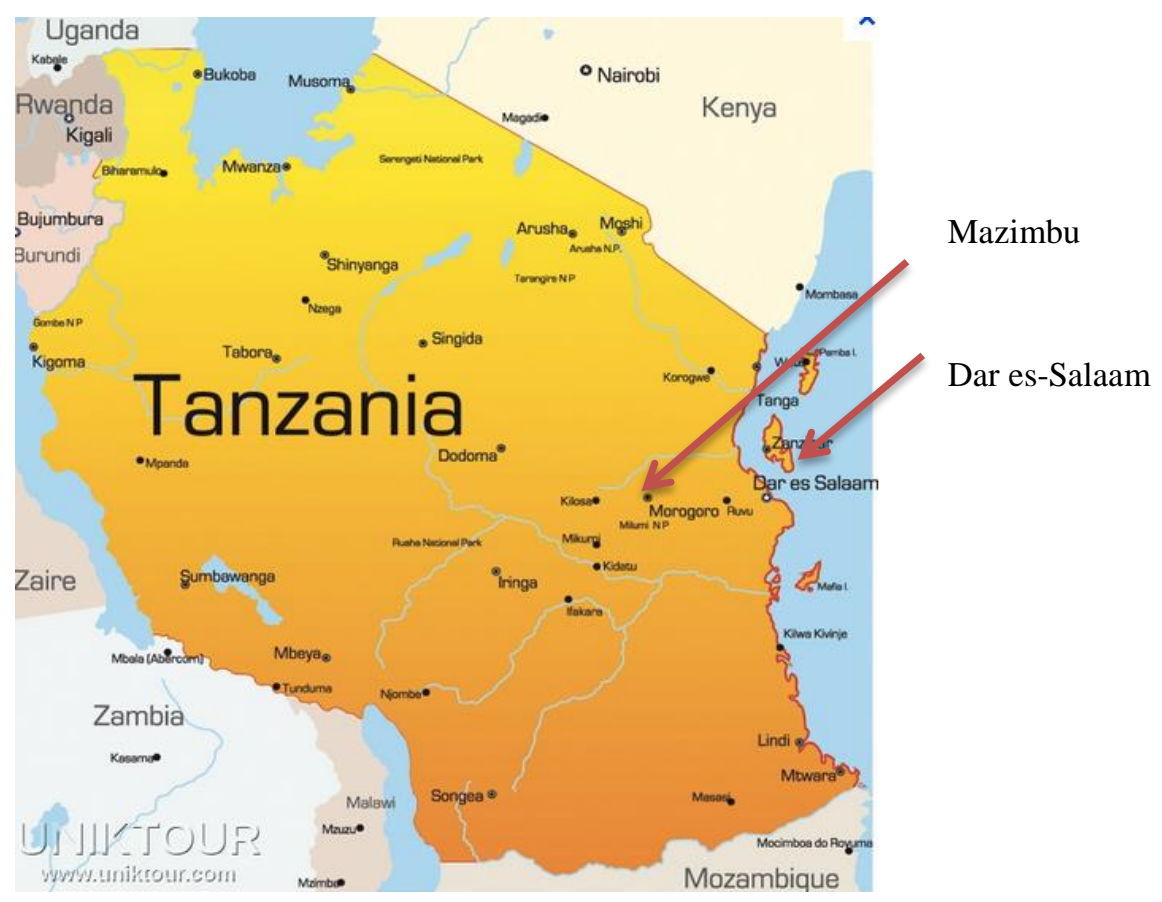

Experimental locations: Dar-es-Salaam and Mazimbu

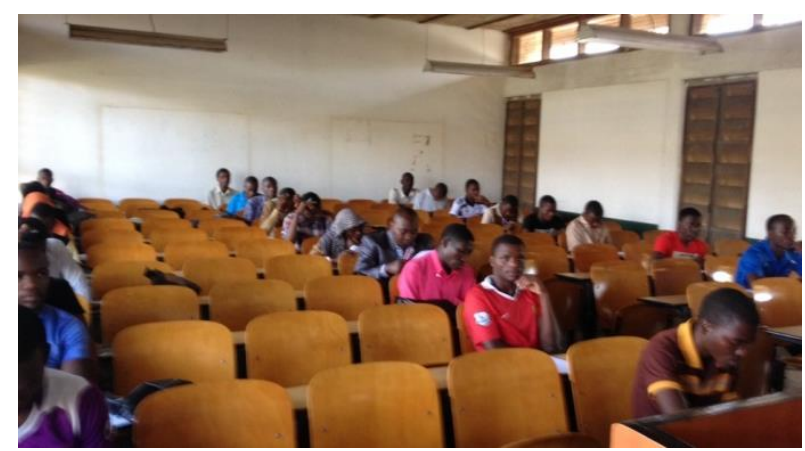

An experimental room

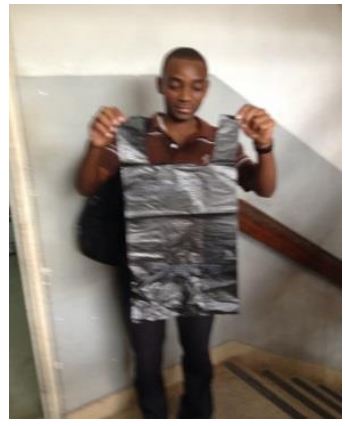

The bags used to transfer money and make decisions 


\section{Appendix 3. Details on the model}

We provide in this Appendix an extended version of the model which is, more or less, self-contained. The propositions presented in the main document are reproduced here, with the same numbering, but in a more precise way. We consider a fixed size population consisting of a sender (player 0 ) and $n$ intermediaries (player 1 to player $n$ ), indexed by $i$, who interact in a modified sequential dictator game. The utility function is the same for all the players, and defined by:

$$
U\left(\sigma_{i}, r_{i}, \bar{\varphi}_{i}(\theta), \theta\right)=u\left(\left(1-\sigma_{i}\right) r_{i}\right)+f\left(\sigma_{i}, \bar{\varphi}_{i}(\theta), \theta\right) .
$$

In order to simplify the notation we let $U, u$, and $f$ instead of, respectively, $U_{i}, u_{i}$, and $f_{i}$. The function $u$ represents the player's material utility, and $f$ her moral utility. $r_{i}$ is the amount received by player $i$ from the previous player in the game, except for the sender who receives an exogenous amount, normalized to $\mathrm{r}_{0}=1$. Player $i$ chooses the fraction $\sigma_{i} \in[0,1]$ of the amount received she transfers to the next player in the chain. The penultieme player transfers money to an ultimate player, called the recipient. By definition $r_{i} \in[0,1]$ for all $i=0,1, \ldots, n$ but, because we are interested in player $i$ 's behavior, we also assume that she receives a strictly positive amount, so that $r_{i} \in$ $(0,1]$.

We assume that player $i$ has beliefs on the fractions $\sigma_{j}$ the players after her in the chain will transfer to the next player $(j=i+1, \ldots, n)$. We denote by $\bar{\sigma}_{j}(\theta)$ player $i$ 's expected transfer by player $j$ under information $\theta \in$ $\{0,1\}$, and by $\bar{\varphi}_{i}(\theta)=\prod_{j=i+1}^{n} \bar{\sigma}_{j}(\theta)$ the total fraction of her own transfer that player $i$ expects the recipient will receive. Therefore $\left(1-\bar{\varphi}_{i}(\theta)\right)$ is player $i$ 's expected level of relative embezzlement after her in the chain, under information $\theta$. For the last intermediary in the chain, namely player $n$, we necessarily have $\bar{\varphi}_{n}(\theta)=1$. In a standard dictator game, we have $\bar{\varphi}_{0}(\theta)=1 .^{31}$

Hypothesis 1. $u_{1}>0$ and $u_{11}<0$.

Hypothesis 2. There exists $\hat{\sigma}_{i} \in[0,1]$ such $f_{1}\left(\sigma_{i}, . ..\right)>0$ for all $\sigma_{i}<\hat{\sigma}_{i}$, and $f_{1}\left(\sigma_{i}, . ..\right) \leq 0$ for all $\sigma_{i}>\hat{\sigma}_{i}$. Moreover $f_{11} \leq 0$.

\section{Examples of utility functions}

Because $f$ captures player $i$ 's moral concern, we can reasonably assume that $f$ is weakly increasing in its second argument $\left(f_{2} \geq 0\right)$ or, equivalently, weakly decreasing in the expected total relative embezzlement after her in the chain $\left(1-\bar{\varphi}_{i}(\theta)\right)$. We emphasize that this assumption is not required for our results, but the examples of functions $f$ below are consistent with it. The following examples are also consistent with hypotheses 1 and 2.

Example 1: $f\left(\sigma_{i}, \bar{\varphi}_{i}(\theta), \theta\right)=0$.

In example 1 the player has no moral concern. Indeed, a necessary condition for consistency with hypothesis 2 is that $\hat{\sigma}_{i}=0$, a moral ideal which corresponds to no transfer. The solution of the player's utility maximization is, under hypothesis 1 , trivial: She transfers nothing.

Example 2: $f\left(\sigma_{i}, \bar{\varphi}_{i}(\theta), \theta\right)=\gamma \sigma_{i}$, with $\gamma>0$.

In example $2, f$ captures a kind of impure altruism or honesty, in the sense that the player is only concerned by the fraction she transfers, regardless of the amount received by the recipient at the end. In that case, one has $f_{1}>0$,

\footnotetext{
${ }^{31}$ In this context, we can write $\widetilde{U}\left(\sigma_{i}, r_{i}, \theta\right)=U\left(\sigma_{i}, r_{i}, 1, \theta\right)$ and $\tilde{f}\left(\sigma_{i}, \theta\right)=f\left(\sigma_{i}, 1, \theta\right)$, so that the utility is reduced to the expression e $\widetilde{U}\left(\sigma_{i}, r_{i}, \theta\right)=u\left(\left(1-\sigma_{i}\right) r_{i}\right)+\tilde{f}\left(\sigma_{i}, \theta\right)$.
} 
$f_{2}=0$ and, for consistency with hypothesis $2, \hat{\sigma}_{i}=1$. The more the player transfers, the higher her moral satisfaction. Hence, an arbitrage is required here in choosing the value of $\sigma_{i}$. On the one hand, $\sigma_{i}$ decreases the utility $u$ of her final payoff. On the other hand, $\sigma_{i}$ increases her utility resulting from her moral concern, captured by $f$.

Example 3: $f\left(\sigma_{i}, \bar{\varphi}_{i}(\theta), \theta\right)=\gamma \sigma_{i} \bar{\varphi}_{i}(\theta)$, with $\gamma>0$.

In example 3 , the player is concerned by the final expected amount $\sigma_{i} \bar{\varphi}_{i}(\theta)$ of her own transfer received by the recipient, according to her beliefs on the intermediaries' transfers after her in the chain. Notice that $f_{1}>0$ and $f_{2}>$ 0 , so that moral satisfaction increases with $\sigma_{i}$, but also with $\bar{\varphi}_{i}(\theta)$. Hence, expecting more embezzlement after her in the chain - recalling that it is equal to $\left(1-\bar{\varphi}_{i}(\theta)\right)$ - reduces her moral satisfaction. In that case, it is possible that the player transfers more in order to compensate for embezzlement.

Example 4: $f\left(\sigma_{i}, \bar{\varphi}_{i}(\theta), \theta\right)=-\gamma\left(\hat{\sigma}_{i}-\sigma_{i}\right)^{2}$, with $\hat{\sigma}_{i} \in[0,1]$ and $\gamma>0$.

In example 4 , the player is characterized by a moral ideal $\hat{\sigma}_{i}$, so that any deviation of $\sigma_{i}$ from this ideal (which works as a moral reference point) will decrease the utility resulting from her moral concern. We have $f_{1}>0$ for all $\sigma_{i}<\hat{\sigma}_{i}$ and $f_{1}<0$ for all $\sigma_{i}>\hat{\sigma}_{i}$, and $f_{2}=0$. As in example 1 , the player is only concerned by the fraction she transfers or the deviation from her moral ideal - and not by the amount received by the recipient.

Example 5: $f\left(\sigma_{i}, \bar{\varphi}_{i}(\theta), \theta\right)=\gamma_{1} \bar{\varphi}_{i}(\theta)-\gamma_{2}\left(\hat{\sigma}_{i}-\sigma_{i}\right)^{2}$, with $\hat{\sigma}_{i} \in[0,1]$ and $\gamma_{1}, \gamma_{2}>0$.

Example 5 is such that $f_{1}>0$ for all $\sigma_{i}<\hat{\sigma}_{i}$ and $f_{1}<0$ for all $\sigma_{i}>\hat{\sigma}_{i}$ and, contrary to the previous case, $f_{2}>0$. We notice that the quadratic term which captures the deviation cost (or moral cost) is independent on $\bar{\varphi}_{i}(\theta)$ here.

Example 6: $f\left(\sigma_{i}, \bar{\varphi}_{i}(\theta), \theta\right)=\gamma_{1} \bar{\varphi}_{i}(\theta)-\gamma_{2} \bar{\varphi}_{i}(\theta)\left(\hat{\sigma}_{i}-\sigma_{i}\right)^{2}$, with $\hat{\sigma}_{i} \in[0,1]$ and $\gamma_{1} \geq \gamma_{2}>0$.

Example 6 is comparable to the previous one, but captures two effects: Deviating from the moral ideal $\hat{\sigma}_{i}$ reduces the player's moral satisfaction, but the cost is smaller as $\bar{\varphi}_{i}(\theta)$ is small - or equivalently as the expected total relative embezzlement after her in the chain $\left(1-\bar{\varphi}_{i}(\theta)\right)$ is high. We have $f_{1}>0$ for all $\sigma_{i}<\hat{\sigma}_{i}$ and $f_{1}<0$ for all $\sigma_{i}>\hat{\sigma}_{i}$, and $f_{2}=\gamma_{1}-\gamma_{2}\left(\hat{\sigma}_{i}-\sigma_{i}\right)^{2}$ because $\gamma_{1} \geq \gamma_{2}>0$ and $\left(\hat{\sigma}_{i}-\sigma_{i}\right)^{2} \in[0,1]$. We emphasize that, contrary to all the previous cases (despite example 3 ), the cross derivatives $f_{12}$ and $f_{21}$ are non-zero here.

Example 7: $f\left(\sigma_{i}, \bar{\varphi}_{i}(\theta), \theta\right)=-\gamma_{1} \max \left\{\sigma_{i} \bar{\varphi}_{i}(\theta)-\left(1-\sigma_{i}\right) r_{i} ; 0\right\}-\gamma_{2} \max \left\{\left(1-\sigma_{i}\right) r_{i}-\sigma_{i} \bar{\varphi}_{i}(\theta) ; 0\right\}$, with $\gamma_{1} \geq \gamma_{2}>0$.

In example 7, the utility $U$ we obtained is quite similar to the Fehr and Schmidt (1999)'s utility function where $\gamma_{1}$ [resp. $\gamma_{2}$ ] is, in their terminology, the parameter of disadvantageous [resp. advantageous] inequality aversion. Notice that the player only compares her monetary payoff $\left(1-\sigma_{i}\right) r_{i}$ to the one she expects the recipient will obtain, namely $\sigma_{i} \bar{\varphi}_{i}(\theta)$. The only difference with the Fehr and Schmidt's model is that the utility $u$ resulting from the monetary payoff is strictly concave here, whereas it is linear in the Fehr and Schmidt's model. This utility function is rationalisable in our model by assuming that $\hat{\sigma}_{i}=r_{i} /\left(r_{i}+\bar{\varphi}_{i}(\theta)\right)$, which corresponds to the fraction player $i$ has to transfer in order to equalize her own payoff to the one she expects the recipient will obtain.

Notice that, in all the previous examples, we considered that the direct effect of information is null, or equivalently letting $f_{3}=0$. We do not provide examples here with $f_{3} \neq 0$. Propositions 1.a and 1.b are detailed versions of proposition 1 in the main text. 
Proposition 1.a. Assume that the player's preferences can be represented by the utility function in equation (1), and assume that hypotheses 1 and 2 are satisfied. Moreover, let $\hat{\sigma}_{i} \in[0,1]$ be the player's moral ideal. Then, there exists a unique donation $\sigma_{i}$ that maximizes the player's preferences, denoted $\sigma_{i}{ }^{*}$, which is such that $\sigma_{i}{ }^{*} \in\left[0, \hat{\sigma}_{i}\right]$.

Proof of Proposition 1.a. Let $\theta \in\{0,1\}, \bar{\varphi}_{i}(\theta) \in[0,1]$ and $\hat{\sigma}_{i} \in[0,1]$ be fixed, and assume that hypotheses 1 and 2 are satisfied. First notice that $U_{1}\left(\sigma_{i}, r_{i}, \bar{\varphi}_{i}(\theta), \theta\right)=-r_{i} u_{1}\left(\left(1-\sigma_{i}\right) r_{i}\right)+f_{1}\left(\sigma_{i}, \bar{\varphi}_{i}(\theta), \theta\right)$ and that $U_{11}\left(\sigma_{i}, r_{i}, \bar{\varphi}_{i}(\theta), \theta\right)=r_{i}{ }^{2} u_{11}\left(\left(1-\sigma_{i}\right) r_{i}\right)+f_{11}\left(\sigma_{i}, \bar{\varphi}_{i}(\theta), \theta\right)$. Uniqueness of a maximum $\sigma_{i}{ }^{*}$ results from the fact that $U_{11}<0$ because $u_{11}<0$ and $f_{11} \leq 0$, together with $r_{i} \in(0,1]$ by definition. Then, the first order condition for the maximization of $U$, according to $\sigma_{i}$, yields:

$$
\begin{array}{ll}
r_{i} u_{1}\left(\left(1-\sigma_{i}^{*}\right) r_{i}\right) \geq f_{1}\left(\sigma_{i}^{*}, \bar{\varphi}_{i}(\theta), \theta\right), & \text { if } \sigma_{i}^{*}=0, \\
r_{i} u_{1}\left(\left(1-\sigma_{i}^{*}\right) r_{i}\right)=f_{1}\left(\sigma_{i}^{*}, \bar{\varphi}_{i}(\theta), \theta\right), & \text { if } \sigma_{i}^{*} \in(0,1), \\
r_{i} u_{1}\left(\left(1-\sigma_{i}^{*}\right) r_{i}\right) \leq f_{1}\left(\sigma_{i}^{*}, \bar{\varphi}_{i}(\theta), \theta\right), & \text { if } \sigma_{i}^{*}=1 .
\end{array}
$$

We have to prove that, if $\hat{\sigma}_{i} \in[0,1]$, then $\sigma_{i}{ }^{*} \leq \hat{\sigma}_{i}$. Let us prove this assertion by contradiction. Assume that $\sigma_{i}{ }^{*}>\hat{\sigma}_{i}$. From hypothesis 2 , we have $f_{1}\left(\sigma_{i}{ }^{*}, \ldots\right) \leq 0$. Because $r_{i} u_{1}\left(\left(1-\sigma_{i}{ }^{*}\right) r_{i}\right)>0$ by hypothesis $1\left(u_{1}>0\right)$ and the fact that $r_{i} \in(0,1]$, the only possibility by the first order condition in equation (2) is $\sigma_{i}{ }^{*}=0$. Since $\sigma_{i}{ }^{*}>\hat{\sigma}_{i}$ by assumption, we necessarily have $\hat{\sigma}_{i} \notin[0,1]$, which is impossible.

Proposition 1.a establishes that the player will never transfer more than her moral ideal. If we observe that a player transfers a strictly positive amount, we can deduce from our model that her moral ideal is greater than the amount sent. Notice that, on the basis of proposition 1.a, $\hat{\sigma}_{i}>0$ is a necessary condition for a non-zero transfer (clearly if $\hat{\sigma}_{i}=0$, then ${\sigma_{i}}^{*}=0$ ), but this condition is not sufficient. We identify in proposition 1.b a necessary and sufficient condition for the player to transfer a non-zero amount.

Proposition 1.b. Assume that the player's preferences can be represented by the utility function in equation (1), and assume that hypotheses 1 and 2 are satisfied. Then the following two statements are equivalent:

(a) The unique transfer $\sigma_{i}^{*} i$ that maximizes the player's preferences is not zero.

(b) $r_{i} u_{1}\left(r_{i}\right)<f_{1}\left(0, \bar{\varphi}_{i}(\theta), \theta\right)$.

Proof of Proposition 1.b. Let $\theta \in\{0,1\}$ and $\bar{\varphi}_{i}(\theta) \in[0,1]$ be fixed. The existence and uniqueness of a maximum $\sigma_{i}^{*}$ results from proposition 1.a.

(b) $\Rightarrow$ (a). By statement (b) we have $r_{i} u_{1}\left(\left(1-\sigma_{i}\right) r_{i}\right)<f_{1}\left(\sigma_{i}, \bar{\varphi}_{i}(\theta), \theta\right)$ when $\sigma_{i}=0$. From the first order condition in equation (2), $\sigma_{i}{ }^{*}$ cannot be zero. Equivalently, $\sigma_{i}{ }^{*}$ is such that $r_{i} u_{1}\left(\left(1-\sigma_{i}{ }^{*}\right) r_{i}\right) \leq f_{1}\left(\sigma_{i}{ }^{*}, \bar{\varphi}_{i}(\theta), \theta\right)$, so that $\sigma_{i}{ }^{*} \in$ $(0,1]$.

(a) $\Rightarrow$ (b). By assuming statement (a), there exists $\sigma_{i}{ }^{*} \in(0,1]$ such that $r_{i} u_{1}\left(\left(1-\sigma_{i}{ }^{*}\right) r_{i}\right)=f_{1}\left(\sigma_{i}{ }^{*}, \bar{\varphi}_{i}(\theta), \theta\right)$ if $\sigma_{i}{ }^{*} \in(0,1)$, and $r_{i} u_{1}\left(\left(1-\sigma_{i}{ }^{*}\right) r_{i}\right) \leq f_{1}\left(\sigma_{i}{ }^{*}, \bar{\varphi}_{i}(\theta), \theta\right)$ if $\sigma_{i}{ }^{*}=1$. From hypotheses 1 and $2, u_{11}<0$ and $f_{11} \leq 0$. Hence for a given $r_{i}, r_{i} u_{1}\left(\left(1-\sigma_{i}\right) r_{i}\right)$ strictly decreases as $\sigma_{i}$ decreases, and $f_{1}\left(\sigma_{i}, \bar{\varphi}_{i}(\theta), \theta\right)$ weakly increases as $\sigma_{i}$ decreases. Thus, we have $r_{i} u_{1}\left(\left(1-\sigma_{i}\right) r_{i}\right)<f_{1}\left(\sigma_{i}, \bar{\varphi}_{i}(\theta), \theta\right)$ for all $\sigma_{i}<\sigma_{i}{ }^{*}$. Such a $\sigma_{i}$ exists because $\sigma_{i}{ }^{*}>0$. Hence $r_{i} u_{1}\left(r_{i}\right)<f_{1}\left(0, \bar{\varphi}_{i}(\theta), \theta\right)$. 
According to proposition 1.b, the player makes a strictly positive transfer if and only if she has a minimal moral concern. Indeed, according to statement (b) which can also be written $U_{1}\left(0, r_{i}, \bar{\varphi}_{i}(\theta), \theta\right)>0$, if the player choose $\sigma_{i}=0$, then an infinitesimal transfer strictly increases his utility $U$. In other terms, the marginal utility loss due to a diminution of the monetary payoff is more than compensated by the marginal increase in the moral utility $f$. This is the meaning of minimal moral concern in our model. If statement (b) is not true, then the unique transfer that maximizes the player's preferences is $\sigma_{i}{ }^{*}=0$.

Notice that the previous result is true regardless of the player's beliefs about the transfers of the intermediaries after her in the chain. If she anticipates that they will transfer nothing $\left(\bar{\varphi}_{i}(\theta)=0\right)$, then the player transfers a positive amount if and only if $r_{i} u_{1}\left(r_{i}\right)<f_{1}(0,0, \theta)$. This last condition can be true, for instance, if she has an intrinsic motivation to give that is independent of the amount finally obtained by the recipient, such as warmglow giving (as in example 2).

Proposition 2. Assume that the player's preferences can be represented by the utility function in equation (1) and assume that hypotheses 1 and 2 are satisfied. Moreover, let $\sigma_{i}{ }^{* 0}$ and $\sigma_{i}^{* 1}$ denote the transfers that maximize, respectively, the utilities $U\left(\sigma_{i}, r_{i}, \bar{\varphi}_{i}{ }^{0}(\theta), \theta\right)$ and $U\left(\sigma_{i}, r_{i}, \bar{\varphi}_{i}{ }^{1}(\theta), \theta\right)$ with $\bar{\varphi}_{i}{ }^{0}(\theta), \bar{\varphi}_{i}{ }^{1}(\theta) \in[0,1]$, such that at least one of the two optimal transfers, $\sigma_{i}{ }^{* 0}$ and ${\sigma_{i}}^{* 1}$, is an interior solution. The following two statements are equivalent:

(a) For all $\bar{\varphi}_{i}{ }^{0}(\theta), \bar{\varphi}_{i}{ }^{1}(\theta) \in[0,1]$, if $\bar{\varphi}_{i}{ }^{0}(\theta) \leq \bar{\varphi}_{i}{ }^{1}(\theta)$ then ${\sigma_{i}}^{* 0} \leq{\sigma_{i}}^{* 1}$.

(b) $f_{12} \geq 0$.

Proof of Proposition 2. $\theta \in\{0,1\}$ is an exogenous parameter and thus it is fixed. First notice that if at least one of the two optimal transfers $\sigma_{i}{ }^{* 0}$ and $\sigma_{i}^{* 1}$ is an interior solution we have, equivalently, $\left(\sigma_{i}^{* 0}, \sigma_{i}^{* 1}\right) \neq(0,0)$ and $\left(\sigma_{i}^{* 0}, \sigma_{i}^{* 1}\right) \neq(1,1)$.

(b) $\Rightarrow$ (a). Let $0 \leq \bar{\varphi}_{i}{ }^{0}(\theta) \leq \bar{\varphi}_{i}{ }^{1}(\theta) \leq 1$ and assume that statement (b) is true. Moreover, assume that hypotheses 1 and 2 are satisfied. If ${\sigma_{i}}^{*}=1$ then, by definition we have $\sigma_{i}{ }^{* 0} \leq \sigma_{i}^{* 1}$ and statement (a) is true. If $\sigma_{i}{ }^{* 1} \in[0,1)$, then we have:

$$
r_{i} u_{1}\left(\left(1-{\sigma_{i}}^{* 1}\right) r_{i}\right) \geq f_{1}\left({\sigma_{i}^{* 1}}^{* 1} \bar{\varphi}_{i}^{1}(\theta), \theta\right) \geq f_{1}\left({\sigma_{i}}^{* 1}, \bar{\varphi}_{i}^{0}(\theta), \theta\right)
$$

The first inequality results from the first order condition of maximization as presented in equation (2), because $\sigma_{i}{ }^{* 1} \in$ $[0,1)$. The second inequality is a consequence of statement (b). Hence we have $r_{i} u_{1}\left(\left(1-\sigma_{i}^{* 1}\right) r_{i}\right) \geq$ $f_{1}\left({\sigma_{i}}^{* 1}, \bar{\varphi}_{i}{ }^{0}(\theta), \theta\right)$, where ${\sigma_{i}}^{* 1}$ is probably not the value that maximizes $U\left(., r_{i}, \bar{\varphi}_{i}{ }^{0}(\theta), \theta\right)$. Moreover, $u_{11}<0$ and $f_{11} \leq 0$ by hypotheses 1 and 2 so that, with $r_{i} \in(0,1]$ fixed, $r_{i} u_{1}\left(\left(1-\sigma_{i}\right) r_{i}\right)$ strictly decreases as $\sigma_{i}$ decreases, and $f_{1}\left(\sigma_{i}, \bar{\varphi}_{i}{ }^{0}(\theta), \theta\right)$ weakly increases as $\sigma_{i}$ decreases. We deduce that the optimal amount transferred under the expected intermediaries' transfer $\bar{\varphi}_{i}{ }^{0}(\theta)$, denoted by ${\sigma_{i}}^{* 0}$, is such that ${\sigma_{i}}^{* 0} \leq{\sigma_{i}}^{* 1}$.

(a) $\Rightarrow$ (b). Assume that statement (a) is true, so that $0 \leq \bar{\varphi}_{i}{ }^{0}(\theta) \leq \bar{\varphi}_{i}{ }^{1}(\theta) \leq 1$ and ${\sigma_{i}}^{* 0} \leq{\sigma_{i}}^{* 1}$. If ${\sigma_{i}}^{* 0}={\sigma_{i}}^{* 1}$, recalling that $\left(\sigma_{i}^{* 0}, \sigma_{i}{ }^{* 1}\right) \neq(0,0)$ and $\left(\sigma_{i}^{* 0}, \sigma_{i}^{* 1}\right) \neq(1,1)$ by assumption, we have:

$$
f_{1}\left(\sigma_{i}^{* 0}, \bar{\varphi}_{i}{ }^{0}(\theta), \theta\right)=u_{1}\left(1-{\sigma_{i}}^{* 0}\right)=u_{1}\left(1-{\sigma_{i}}^{* 1}\right)=f_{1}\left(\sigma_{i}^{* 1}, \bar{\varphi}_{i}{ }^{1}(\theta), \theta\right) .
$$

The first and third equalities result from the first order condition in equation (2). We deduce that $f_{1}\left(x, \bar{\varphi}_{i}{ }^{0}(\theta), \theta\right)=$ $f_{1}\left(x, \bar{\varphi}_{i}{ }^{1}(\theta), \theta\right)$ for all $x \in(0,1)$. Now, if ${\sigma_{i}}^{* 0}<{\sigma_{i}}^{* 1}$ we have: 


$$
f_{1}\left({\sigma_{i}}^{* 1},{\bar{\varphi}_{i}}^{0}(\theta), \theta\right) \leq f_{1}\left({\sigma_{i}}^{* 0},{\bar{\varphi}_{i}}^{0}(\theta), \theta\right) \leq u_{1}\left(1-{\sigma_{i}}^{* 0}\right)<u_{1}\left(1-{\sigma_{i}}^{* 1}\right) \leq f_{1}\left({\sigma_{i}}^{* 1},{\bar{\varphi}_{i}}^{1}(\theta), \theta\right) .
$$

The first inequality is a consequence of $f_{11} \leq 0$. The second inequality results from the first order condition in equation (2), by noting that $\sigma_{i}{ }^{* 0} \in[0,1)$ because ${\sigma_{i}}^{* 0}<{\sigma_{i}}^{* 1} \leq 1$. The third inequality follows from $u_{11}<0$. The last inequality results from the first order condition in equation (2), by noting that $\sigma_{i}{ }^{* 1} \in(0,1]$ because $0 \leq{\sigma_{i}}^{* 0}<{\sigma_{i}}^{* 1}$. We deduce that $f_{1}\left({\sigma_{i}}^{* 1}, \bar{\varphi}_{i}{ }^{0}(\theta), \theta\right) \leq f_{1}\left({\sigma_{i}}^{* 1}, \bar{\varphi}_{i}{ }^{1}(\theta), \theta\right)$. By applying the same reasoning, we also have $f_{1}\left({\sigma_{i}}^{* 0}, \bar{\varphi}_{i}{ }^{0}(\theta), \theta\right) \leq f_{1}\left({\sigma_{i}}^{* 0}, \bar{\varphi}_{i}{ }^{1}(\theta), \theta\right)$. By combining the two possible cases $\sigma_{i}{ }^{* 0}=\sigma_{i}{ }^{* 1}$ and ${\sigma_{i}}^{* 0}<{\sigma_{i}}^{* 1}$ we conclude that, if ${\sigma_{i}}^{* 0} \leq{\sigma_{i}}^{* 1}$, then we necessarily have $f_{1}\left(x, \bar{\varphi}_{i}{ }^{0}(\theta), \theta\right) \leq f_{1}\left(x, \bar{\varphi}_{i}{ }^{1}(\theta), \theta\right)$ for all $x \in[0,1]$.

Proposition 2 actually demonstrates only one case among the three mentioned in the same Proposition in the main text. But the two other cases are direct corollaries. This result identifies the restriction to be placed on the utility function in order to guarantee that an increase in the anticipated embezzlement - from state 1 to state 0 in the Proposition, represented by the relation $\bar{\varphi}_{i}{ }^{0}(\theta) \leq \bar{\varphi}_{i}{ }^{1}(\theta)$ - reduces the player's optimal transfer. It is worth emphasizing that the restriction only concerns function $f$.

Proposition 3. Assume that the player's preferences can be represented by the utility function in equation (1) and assume that hypotheses 1 and 2 are satisfied. Moreover, assume that transparency has no impact on the anticipated embezzlement or, equivalently, $\bar{\varphi}_{i}\left(\theta^{0}\right)=\bar{\varphi}_{i}\left(\theta^{1}\right)=\bar{\varphi}_{i}$ for all $\theta^{0}, \theta^{1} \in\{0,1\}$. Now let $\sigma_{i}{ }^{* 0}$ and $\sigma_{i}{ }^{* 1}$ denote the transfers that maximize, respectively, the utilities $U\left(\sigma_{i}, r_{i}, \bar{\varphi}_{i}, \theta^{0}\right)$ and $U\left(\sigma_{i}, r_{i}, \bar{\varphi}_{i}, \theta^{1}\right)$ with $\theta^{0}, \theta^{1} \in\{0,1\}$, such that at least one of the two optimal transfers, $\sigma_{i}{ }^{* 0}$ and ${\sigma_{i}}^{* 1}$, is an interior solution. The following two statements are equivalent:

(a) For all $\theta^{0}, \theta^{1} \in\{0,1\}$, if $\theta^{0} \leq \theta^{1}$, then $\sigma_{i}{ }^{* 0} \leq{\sigma_{i}}^{* 1}$.

(b) $f_{1}(., ., 0) \leq f_{1}(., ., 1)$.

Proof of Proposition 3. Note that, if we had defined information as a continuous parameter, so that $\theta \in[0,1]$, then statement (b) would have to be replaced by the condition $f_{13} \geq 0$. The proof here uses exactly the same arguments as the ones used in the proof of proposition 2

Proposition 3 investigates the direct effect of information/transparency on the optimal transfer, by controlling the indirect effect which can play a role through the player's beliefs about the transfer of all the players after her in the chain. In that case, the player's optimal transfer weakly increases with transparency - from $\theta=0$ to $\theta=1-$ if and only if the marginal moral utility of the transfer, also weakly increases with transparency.

Hypothesis 3. $\bar{\varphi}_{i}(0) \leq \bar{\varphi}_{i}(1)$.

Hypothesis 4. $f_{1}(., ., 0) \leq f_{1}(., ., 1)$.

Hypothesis 3 states that a player anticipates that transparency cannot increase embezzlement of all the intermediaries after her in the chain. Hypothesis 4 is equivalent to assume that the direct effect of information is such that a player does not transfer less under transparency (see proposition 3). 
Proposition 4. Assume that the player's preferences can be represented by the utility function in equation (1) and assume that hypotheses 1 to 4 are satisfied. Moreover, let $\sigma_{i}{ }^{* 0}$ and $\sigma_{i}{ }^{* 1}$ denote the transfers that maximize, respectively, the utilities $U\left(\sigma_{i}, r_{i}, \bar{\varphi}_{i}(0), 0\right)$ and $U\left(\sigma_{i}, r_{i}, \bar{\varphi}_{i}(1), 1\right)$. If $f_{12} \geq 0$, then $\sigma_{i}{ }^{* 0} \leq \sigma_{i}{ }^{* 1}$. If $f_{12}<0$, then the ranking between $\sigma_{i}^{* 0}$ and $\sigma_{i}{ }^{* 1}$ is ambiguous.

Proof of Proposition 4. Assume that hypotheses 1 to 4 are satisfied. If ${\sigma_{i}}^{* 1}=1$, then by definition ${\sigma_{i}}^{* 0} \leq{\sigma_{i}}^{* 1}$. If $\sigma_{i}^{* 1} \in[0,1)$, then we have:

$$
r_{i} u_{1}\left(\left(1-{\sigma_{i}}^{* 1}\right) r_{i}\right) \geq f_{1}\left({\sigma_{i}^{*}}^{* 1}, \bar{\varphi}_{i}(1), 1\right) \geq f_{1}\left({\sigma_{i}}^{* 1}, \bar{\varphi}_{i}(1), 0\right) \geq f_{1}\left(\sigma_{i}^{* 1}, \bar{\varphi}_{i}(0), 0\right)
$$

The first inequality results from the first order condition of maximization as presented in equation (2), because $\sigma_{i}{ }^{* 1} \in$ $[0,1)$. The second inequality is a consequence of hypothesis 4 . If, in addition, we assume that $f_{12} \geq 0$, then the third inequality follows from hypothesis 3 . One obtains $r_{i} u_{1}\left(\left(1-\sigma_{i}{ }^{* 1}\right) r_{i}\right) \geq f_{1}\left(\sigma_{i}{ }^{* 1}, \bar{\varphi}_{i}(0), 0\right)$, where ${\sigma_{i}}^{* 1}$ is probably not the value that maximizes $U\left(., r_{i}, \bar{\varphi}_{i}(0), 0\right)$. Moreover, $u_{11}<0$ and $f_{11} \leq 0$ by hypotheses 1 and 2 so that, with $r_{i} \in(0,1]$ fixed, $r_{i} u_{1}\left(\left(1-\sigma_{i}\right) r_{i}\right)$ strictly decreases as $\sigma_{i}$ decreases, and $f_{1}\left(\sigma_{i}, \bar{\varphi}_{i}(0), 0\right)$ weakly increases as $\sigma_{i}$ decreases. We deduce that the optimal amount transferred under $\theta=0$, denoted by $\sigma_{i}^{* 0}$, is such that ${\sigma_{i}}^{* 0} \leq{\sigma_{i}}^{* 1}$. To conclude the proof note that, if $f_{12}<0$, then the sign of the third inequality in equation (6) is reversed, so that the effect of transparency on the player's optimal transfer is ambiguous.

By assuming that transparency cannot increase anticipated embezzlement after the player in the chain (hypothesis 3), and assuming that the direct effect of transparency affects positively the optimal transfer (hypothesis 4), Proposition 4 identifies the role of the cross-derivative $f_{12}$ on the optimal transfer. It follows that the player's does not decrease her transfer under transparency if $f_{12} \geq 0$. Otherwise, the impact of information is ambiguous. We emphasize that, for the last player in the chain, only the direct effect of information impacts her transfer decision. In that case, under hypothesis 4 , the optimal transfer of this last player does not decrease with transparency (see proposition 3).

Finally, we investigate the impact of the number of intermediaries on the player's behavior. We can reasonably assume that total embezzlement, expected by the player after her in the chain, does not decrease with the number of intermediaries. More precisely, if $\bar{\varphi}_{i}^{n}(\theta)=\prod_{j=i+1}^{n} \bar{\sigma}_{j}(\theta)$ denotes the total fraction of the player's transfer she expects that the recipient will obtain after the chain of the $n$ intermediaries, we assume the following hypothesis.

Hypothesis 5. $\bar{\varphi}_{i}{ }^{n+1}(\theta) \leq \bar{\varphi}_{i}^{n}(\theta)$.

For instance, hypothesis 5 is true if the player anticipates a similar (relative) transfer for each intermediary $\left(\bar{\sigma}_{j}=\right.$ $c \in[0,1]$ for all $j=i+1, \ldots, n$, so that $\bar{\varphi}_{i}{ }^{n+1}(\theta)=c \bar{\varphi}_{i}{ }^{n}(\theta) \leq \bar{\varphi}_{i}{ }^{n}(\theta)$ ). As a corollary of proposition 2, we also obtain the following result.

Proposition 5. Assume that the player's preferences can be represented by the utility function in equation (1) and assume that hypotheses 1, 2 and 5 are satisfied. The player's optimal transfer is not lower [resp. is not higher, resp. is equal] with a short intermediaries' chain after her, as compared to a long chain, if and only if $f_{12} \geq 0$ [resp. $f_{12} \leq 0$, resp. $\left.f_{12}=0\right]$. 